\title{
Top-down and bottom-up aerosol-cloud closure: towards understanding sources of uncertainty in deriving cloud shortwave radiative flux
}

\author{
Kevin J. Sanchez ${ }^{1,2}$, Gregory C. Roberts ${ }^{1,2}$, Radiance Calmer $^{2}$, Keri Nicoll ${ }^{3,4}$, Eyal Hashimshoni ${ }^{5}$, Daniel Rosenfeld ${ }^{5}$, \\ Jurgita Ovadnevaite $^{6}$, Jana Preissler ${ }^{6}$, Darius Ceburnis ${ }^{6}$, Colin O'Dowd ${ }^{6}$, and Lynn M. Russell ${ }^{1}$ \\ ${ }^{1}$ Scripps Institution of Oceanography, University of California, San Diego, CA, USA \\ ${ }^{2}$ Centre National de Recherches Météorologiques, Météo-France \& CNRS UMR3589, Toulouse, France \\ ${ }^{3}$ Department of Meteorology, University of Reading, Reading, UK \\ ${ }^{4}$ Department of Electronic and Electrical Engineering, University of Bath, Bath, UK \\ ${ }^{5}$ Institute of Earth Sciences, The Hebrew University of Jerusalem, Jerusalem, Israel \\ ${ }^{6}$ School of Physics and Centre for Climate and Air Pollution Studies, National University of Ireland Galway, \\ Galway, Ireland
}

Correspondence to: Kevin J. Sanchez (kjsanche@ucsd.edu)

Received: 4 March 2017 - Discussion started: 21 March 2017

Revised: 13 July 2017 - Accepted: 15 July 2017 - Published: 22 August 2017

\begin{abstract}
Top-down and bottom-up aerosol-cloud shortwave radiative flux closures were conducted at the Mace Head Atmospheric Research Station in Galway, Ireland, in August 2015. This study is part of the BACCHUS (Impact of Biogenic versus Anthropogenic emissions on Clouds and Climate: towards a Holistic UnderStanding) European collaborative project, with the goal of understanding key processes affecting aerosol-cloud shortwave radiative flux closures to improve future climate predictions and develop sustainable policies for Europe. Instrument platforms include ground-based unmanned aerial vehicles (UAVs) ${ }^{1}$ and satellite measurements of aerosols, clouds and meteorological variables. The ground-based and airborne measurements of aerosol size distributions and cloud condensation nuclei (CCN) concentration were used to initiate a 1-D microphysical aerosol-cloud parcel model (ACPM). UAVs were equipped for a specific science mission, with an optical particle counter for aerosol distribution profiles, a cloud sensor to measure cloud extinction or a five-hole probe for 3$\mathrm{D}$ wind vectors. UAV cloud measurements are rare and have only become possible in recent years through the miniaturization of instrumentation. These are the first UAV measurements at Mace Head. ACPM simulations are compared to
\end{abstract}

\footnotetext{
${ }^{1}$ The regulatory term for $\mathrm{UAV}$ is remotely piloted aircraft (RPA).
}

in situ cloud extinction measurements from UAVs to quantify closure in terms of cloud shortwave radiative flux. Two out of seven cases exhibit sub-adiabatic vertical temperature profiles within the cloud, which suggests that entrainment processes affect cloud microphysical properties and lead to an overestimate of simulated cloud shortwave radiative flux. Including an entrainment parameterization and explicitly calculating the entrainment fraction in the ACPM simulations both improved cloud-top radiative closure. Entrainment reduced the difference between simulated and observation-derived cloud-top shortwave radiative flux $(\delta \mathrm{RF})$ by between 25 and $60 \mathrm{~W} \mathrm{~m}^{-2}$. After accounting for entrainment, satellite-derived cloud droplet number concentrations (CDNCs) were within $30 \%$ of simulated CDNC. In cases with a well-mixed boundary layer, $\delta \mathrm{RF}$ is no greater than $20 \mathrm{~W} \mathrm{~m}^{-2}$ after accounting for cloud-top entrainment and up to $50 \mathrm{~W} \mathrm{~m}^{-2}$ when entrainment is not taken into account. In cases with a decoupled boundary layer, cloud microphysical properties are inconsistent with ground-based aerosol measurements, as expected, and $\delta \mathrm{RF}$ is as high as $88 \mathrm{~W} \mathrm{~m}^{-2}$, even high $\left(>30 \mathrm{~W} \mathrm{~m}^{-2}\right)$ after accounting for cloud-top entrainment. This work demonstrates the need to take in situ measurements of aerosol properties for cases where the boundary layer is decoupled as well as consider cloud-top 
entrainment to accurately model stratocumulus cloud radiative flux.

\section{Introduction}

One of the greatest challenges in studying cloud effects on climate are that the clouds are literally out of reach. Many ground-based measurement sites have a long historical record that are useful for identifying climatological trends; however, it is difficult to quantify such trends in cloud microphysical and radiative properties at these stations based solely on remote-sensing techniques such as radar and lidar. In situ aerosol measurements at the surface are often used to estimate cloud properties aloft, but the simulations used to estimate above surface conditions require many idealized assumptions such as a well-mixed boundary layer (BL) and adiabatic parcel lifting. Satellites have the advantage to infer cloud properties over a much larger area than groundbased observations; however, they can only see the uppermost cloud layer, and satellites need in situ observations to improve their retrievals. In this study, we combine groundbased and airborne measurements with satellite observations to determine cloud radiative properties and compare these results to an aerosol-cloud parcel model (ACPM) to identify sources of uncertainty in aerosol-cloud interactions.

The atmospheric research station at Mace Head has been a research platform for studying trace gases, aerosols and meteorological variables since 1958 (O'Connor et al., 2008). The station is uniquely exposed to a variety of air masses, such as clean marine air and polluted European air. Over the long history of observations and numerous field campaigns held at the Mace Head Atmospheric Research Station, few airborne field experiments have been conducted. During the PARFORCE campaign in September 1998, aerosol and trace gas measurements were made to map coastal aerosol formation (O'Dowd et al., 2001). During the second PARFORCE campaign in June 1999, measurements of sea spray plumes were made on an aircraft installed with a lidar (Kunz et al., 2002). In the NAMBLEX campaign in August 2002, flights were conducted to measure aerosol chemical and physical properties in the vicinity of Mace Head (Heard et al., 2006; Norton et al., 2006; Coe et al., 2006). None of the research flights thus far have studied aerosol-cloud interactions and cloud radiative properties at Mace Head.

For ground-based observations, it is often assumed that measured species are well mixed throughout the boundary layer. Often this assumption is valid, and many observational studies have shown that models which use groundbased measurements can accurately simulate cloud droplet number concentrations (CDNCs; Russell and Seinfeld, 1998; Conant et al., 2004; Fountoukis et al., 2007), making bottomup closure a viable method for predicting cloud properties. Closure is defined here as the agreement between observa- tions and model simulations of CDNC and cloud-top shortwave radiative flux ( $\delta \mathrm{RF})$. This well-mixed boundary layer simplification, however, has been shown to be inaccurate in many field experiments (e.g., the Atlantic Stratocumulus Transition Experiment (ASTEX; Albrecht et al., 1995) and the Aerosol Characterization Experiments, ACE1 (Bates et al., 1998) and ACE2 (Raes et al., 2000)). Previous studies at Mace Head have shown that decoupled boundary layers can be observed with scanning backscatter lidar measurements (Kunz et al., 2002; Milroy et al., 2012). Such decoupled layers often contain two distinct cloud layers, distinguished as a lower layer within the well-mixed surface mixed layer and a higher decoupled layer between the free troposphere and surface mixed layer (Kunz et al., 2002; Milroy et al., 2012; Stull, 1988). General characteristics associated with decoupled boundary layers are a weak inversion and a decrease in aerosol concentration relative to the surface mixed layer, and they are most commonly occur in relatively deep marine boundary layers (> $1400 \mathrm{~m}$; Jones et al., 2011). Dall'Osto et al. (2010) showed the average height of the surface mixed layer, over Mace Head, varies from 500 to $2000 \mathrm{~m}$, and the decoupled layers have heights ranging from 1500 to $2500 \mathrm{~m}$. Marine boundary layer decoupling is often seen in the tropics and has been attributed to processes that involve cloud heating from cloud-top entrainment, leading to decoupling of the boundary layer (Bretherton and Wyant, 1997; Bates et al., 1998; Albrecht et al., 1995; Zhou et al., 2015; Stevens, 2002). In addition, Bretherton and Wyant (1997) have shown that the decoupling structure is mainly driven by a high latent heat flux that results in a large buoyancy jump across the cloud base. This high latent heat flux is attributed to easterlies bringing air over increasing sea surface temperature, where the boundary layer becomes deeper and more likely to decouple (Albrecht et al., 1995). The cloud layer drives the turbulent motion, and a zone of negative buoyancy flux develops below cloud. The turbulent motion is driven by radiative cooling at cloud top, causing air to sink (Lilly, 1968). The zone of negative buoyancy exists because the deepening of the boundary layer causes the lifting condensation level of the updraft and downdraft to separate. This is important because latent heating in the cloud contributes significantly to the buoyancy in the cloud (Schubert et al., 1979). If this zone of negative buoyancy flux becomes deep enough, it is dynamically favorable for the cloud layer to become decoupled from the cloud layer (Bretherton and Wyant, 1997). Bretherton and Wyant (1997) also show that drizzle can have a substantial impact on enhancing the negative buoyancy flux below cloud, but drizzle is not necessary for the decoupling mechanism they proposed. Other factors, such as the vertical distribution of radiative cooling in the cloud and sensible heat fluxes, play less important roles. Turton and Nicholls (1987) used a two-layer model to show that decoupling can also result from solar heating of the cloud layer, albeit only during the day. Furthermore, Nicholls and Leighton (1986) showed observations of decoupled clouds with cloud-top radiative 
cooling, and the resulting in-cloud eddies do not mix down to the surface (further suggesting radiative cooling plays a less important role). Russell et al. (1998) and Sollazzo et al. (2000) showed that in a decoupled atmosphere the two distinct layers have similar characteristics (e.g., aerosol and trace gases composition), with different aerosol concentrations that gradually mix with each other, mixing air from the surface mixed layer into the decoupled layer and vice versa. These previous studies also show that aerosol concentrations in the decoupled layer are lower than those in the surface mixed layer, implying an overestimation in cloud shortwave radiative flux when using ground-based aerosol measurements.

Satellite measurements of microphysical properties, such as CDNC, have the potential to be independent of groundbased measurements and therefore be reliable for studying decoupled clouds. Satellite estimates of CDNC have only become possible recently due to the increased resolution in measurements (Rosenfeld et al., 2012, 2014, 2016; Painemal and Zuidema, 2011). Therefore, current measurements still require ground-based validation until the method is further developed.

The focus of this manuscript is on the top-down closure between satellite retrievals and airborne measurements of cloud microphysical properties, as well as traditional bottomup closure coupling below and in-cloud measurements of cloud condensation nuclei (CCN), updraft and cloud microphysical properties. In situ measurements of CDNC are not available, so bottom-up closure is expressed in terms of cloud-top shortwave radiative flux rather than CDNC, and top-down closure of satellite CDNC is compared to ACPMsimulated CDNC. The Methods section describes how observations were collected, as well as the methods for estimating CDNC with satellite measurements and calculating shortwave radiative flux with the ACPM. The Results/discussion section summarizes the bottom-up and top-down closure for coupled and decoupled clouds and quantifies the differences in cloud shortwave radiative flux for cases that were affected by cloud-top entrainment.

\section{Methods}

The August 2015 campaign at the Mace Head Atmospheric Research Station (Galway, Ireland; $53.33^{\circ} \mathrm{N}, 9.90^{\circ} \mathrm{W}$ ) focused on aerosol-cloud interactions at the eastern North Atlantic Ocean by coupling ground-based in situ and remotesensing observations with airborne and satellite observations. This section summarizes the measurements used for this study and the model used to simulate the observations.

\subsection{Ground-based measurements}

At the Mace Head research site, aerosol instruments are located in the laboratory at about $100 \mathrm{~m}$ from the coastline.

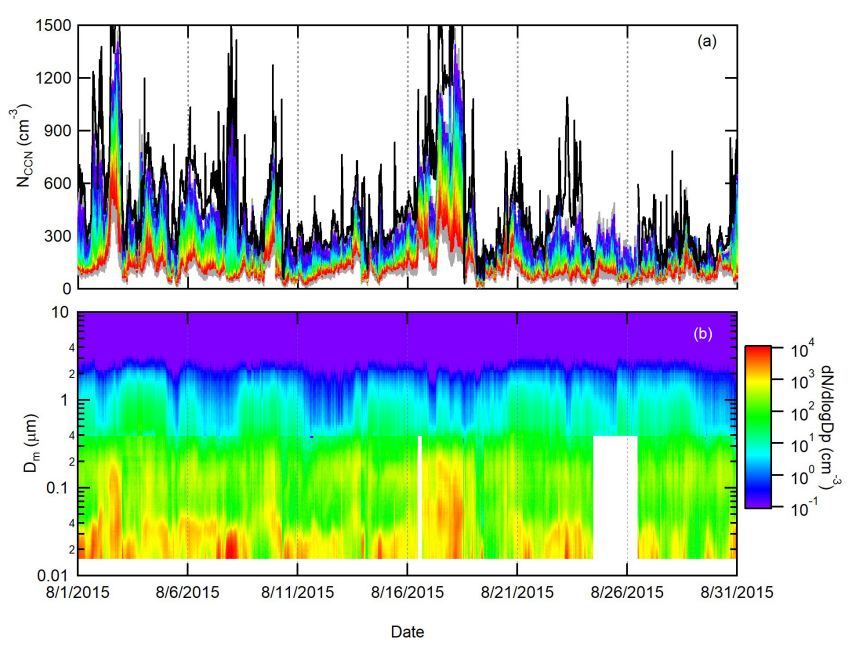

Figure 1. Time series for the month of August 2015 at Mace Head, Ireland, of ground-based CCN concentrations (a) and merged SMPS and APS number size distributions (b).

They are connected to the laminar flow community air sampling system, which is constructed from a $100 \mathrm{~mm}$ diameter stainless-steel pipe with the main inlet at $10 \mathrm{~m}$ above ground level, so that samples are not impacted by immediate coastal aerosol production mechanisms, such as wave breaking and biological activity (Norton et al., 2006; O'Dowd et al., 2004, 2014; Coe et al., 2006; Rinaldi et al., 2009). The performance of this inlet is described in Kleefeld et al. (2002). Back trajectories during the period of the experiment show that the origin of air masses is predominantly from the North Atlantic; therefore, the air masses sampled at Mace Head generally represent clean open-ocean marine aerosol. Mace Head contains a variety of aerosol sampling instrumentation, spanning particle diameter range of $0.02-20 \mu \mathrm{m}$. Size spectral measurements are performed at a relative humidity $(\mathrm{RH})<40 \%$ using Nafion driers. Supermicron particle size distributions were measured using an Aerodynamic Particle Sizer (APS, TSI model 3321, $0.5<D_{\mathrm{p}}<20 \mu \mathrm{m}$ ). The remaining submicron aerosol size range was retrieved from a scanning mobility particle sizer (SMPS, $0.02<D_{\mathrm{p}}<0.5 \mu \mathrm{m}$ ), comprised of a differential mobility analyzer (DMA, TSI model 3071), a condensation particle counter (TSI model $3010, D_{\mathrm{p}}>10 \mathrm{~nm}$ ) and a $\mathrm{Kr}-85$ aerosol neutralizer (TSI 3077). CCN measurements were performed with a miniature continuous-flow stream-wise thermal gradient chamber, which measures the concentration of activated $\mathrm{CCN}$ over a range of supersaturations (Roberts and Nenes, 2005). During this study, the supersaturation range spanned 0.2 to $0.82 \%$. Aerosol hygroscopicity was calculated using $\kappa$-Köhler theory (Petters and Kreidenweis, 2007) with the sampled CCN concentrations at a particular supersaturation and corresponding integrated aerosol number concentration at a critical diameter (Roberts et al., 2001). Figure 1 shows time series of CCN spectra and aerosol number size distributions throughout the campaign. 
The ground-based remote-sensing measurements utilized in this study are the $35.5 \mathrm{GHz} \mathrm{Ka}$-band Doppler cloud radar MIRA36 (Melchionna et al., 2008; Goersdorf et al., 2015) to obtain vertical velocity distributions at cloud base and the Jenoptik CHM15K ceilometer (Heese et al., 2010; Martucci et al., 2010) to obtain cloud-base height.

\subsection{UAV vertical profiles}

The UAV operations were conducted directly on the coast about $200 \mathrm{~m}$ from the Mace Head Atmospheric Research Station. UAVs were used to collect vertical profiles of standard meteorological variables, temperature (IST, Model P1K0.161.6W.Y.010), pressure (Bs rep Gmbh, Model 15PSIA-HGRADE-SMINI) and relative humidity (IST, P14 Rapid$\mathrm{W})$, as well as aerosol size distributions with an optical particle counter (OPC, Met One Model 212-2), cloud droplet extinction (Harrison and Nicoll, 2014) updraft velocity at cloud base with a five-hole probe. A list of the various UAV flights and their instrumentation is given in Table 1. Measurement errors for the relative humidity and temperature sensors are $\pm 5 \%$ and $\pm 0.5^{\circ} \mathrm{C}$, respectively. As RH sensors are not accurate at high RH $(>90 \%)$, the measured values have been scaled such that RH measurements are $100 \%$ in a cloud. At altitudes where the UAV is known to be in cloud (based on in situ cloud extinction measurements) the air mass is considered saturated $(\mathrm{RH} \sim 100 \%)$. The temperature and relative humidity sensors are protected from solar radiative heating by a thin-walled aluminum shroud positioned outside of the surface layer of the UAV. A helical cone, mounted in front of the sensors, ejects droplets to protect the sensors. The temperature measurements for both cases in which cloud-top entrainment is explored (see Sect. 3.2) are verified to remain in stratocumulus clouds throughout the ascents and descents, and they are not affected by evaporative cooling. The temperature and relative humidity measurements were used to initialize the ACPM below cloud. The UAVs were flown individually in separate missions up to $1.5 \mathrm{~h}$, and each UAV was instrumented to perform a specific science mission (referred to here as aerosol, cloud and 3-D winds).

The OPC measured aerosol number size distributions in eight size bins between 0.3 and $10 \mu \mathrm{m}$ diameter. Aerosols were sampled via a quasi-isokinetic shrouded inlet mounted on the nose of the UAV. Aerosols samples were heated upon entering the UAV ( $\Delta T>5 \mathrm{~K}$ due to internal heating by the electronics), reducing the relative humidity of the sampled air to less than $60 \%$, and decreased with height $(<50 \%$ above $150 \mathrm{~m}$ ) before aerosol size was measured. Figure 2 shows a two-instrument redundancy cross-check between groundbased APS and UAV OPC measurements (collected between 40 and $80 \mathrm{~m}$ a.g.1.) of aerosol sizes, which are in agreement $\left(r^{2}=0.48\right)$.

In-cloud extinction was measured in situ using a miniature optical cloud droplet sensor developed at the University of Reading (Harrison and Nicoll, 2014). The sensor operates
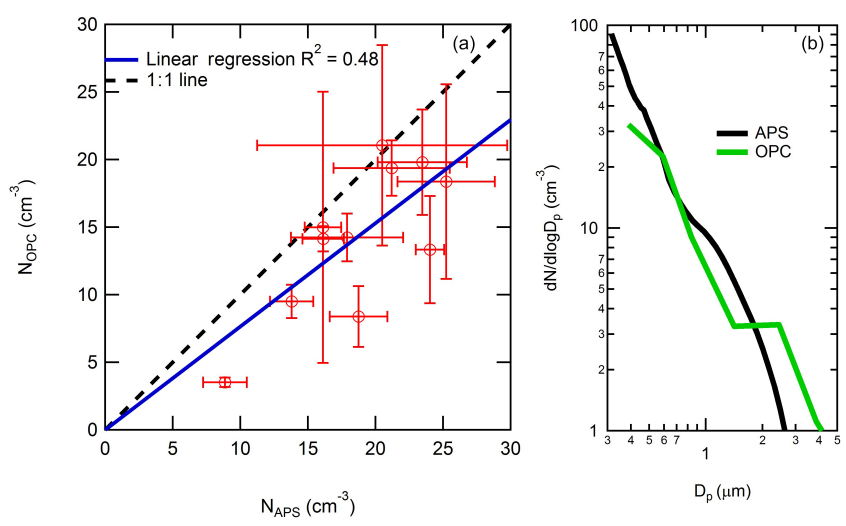

Figure 2. OPC concentrations with particle diameters $\left(D_{\mathrm{p}}\right)$ greater than $0.3 \mu \mathrm{m}$ (a) from $11 \mathrm{UAV}$ research flights, listed in Table 1, plotted against APS concentrations $\left(D_{\mathrm{p}}>0.3 \mu \mathrm{m}\right)$ at Mace Head Atmospheric Research Station (red circles). Error bars represent \pm 1 standard deviation. The points are fit with a linear regression (blue line). OPC data were averaged between 40 and $80 \mathrm{~m}$ a.s.1. OPC and APS number size distributions averaged for the 11 flights (b).

by a backscatter principle using modulated LED light which is backscattered into a central photodiode. Comparison of the sensor with a Cloud Droplet Probe (Droplet Measurement Technologies) demonstrates good agreement for cloud droplet diameters $>5 \mu \mathrm{m}$ (Nicoll et al., 2016). The extinction measurements were used to calculate cloud-top shortwave radiative flux and are further discussed in Sect. 2.4.

Finally, a five-hole probe for measuring three-dimensional wind vectors was mounted on a third UAV. The 3-D wind vectors are determined by subtracting the UAV motion given by an inertial measurement unit (IMU) from the total measured flow obtained by differential pressures in the five-hole probe (Wildmann et al., 2014; Lenschow and Spyers-Duran, 1989; Calmer et al., 2017). UAV five-hole probe measurements were collected along $6 \mathrm{~km}$ long straight and level legs at cloud base. Normalized cloud radar vertical velocity distributions are compared to vertical wind distributions obtained from the UAV in Fig. 3. The positive updraft velocities in Fig. 3 are used to initialize the ACPM to produce simulated cloud droplet size distributions throughout the depth of the cloud. The droplet distributions for each updraft velocity are averaged and weighted by the probability distribution of the measured positive velocities. Differences in results when using the cloud radar updrafts versus the UAV five-hole probe updrafts (Fig. 3) are discussed in Sect. 3.1.2.

\subsection{Satellite measurements}

Research flights with the UAV were conducted in conjunction with satellite overpasses to compare retrieved CDNC and maximum supersaturation $\left(S_{\max }\right)$ with ACPM-simulated values using the NASA Suomi National Polar-orbiting Partnership (NPP) satellite. The satellite estimations of CDNC 
Table 1. UAV research flights conducted at Mace Head, Ireland, and measured parameters in 2015. Flight start and end times are in UTC. NASA's Suomi National Polar-orbiting Partnership satellite overpasses occurred at approximately 13:00 UTC. Measurements include relative humidity $(\mathrm{RH})$, temperature $(T)$, pressure $(P)$, three-dimensional wind vectors (3-D winds), optical particle counter (OPC) and cloud sensor measurements of cloud droplet extinction.

\begin{tabular}{|c|c|c|c|c|c|c|c|c|c|}
\hline Date & Flight & Start time & End time & $\mathrm{RH}$ & $T$ & $P$ & 3-D winds & OPC & Cloud \\
\hline 30-Jul & 4 & $12: 41$ & $13: 19$ & $\mathrm{x}$ & $\mathrm{x}$ & $\mathrm{x}$ & & $\mathrm{x}$ & \\
\hline 30-Jul & 5 & $14: 00$ & $14: 44$ & $\mathrm{x}$ & $\mathrm{x}$ & $\mathrm{x}$ & & & $\mathrm{x}$ \\
\hline 30-Jul & 6 & $16: 04$ & $16: 42$ & $\mathrm{x}$ & $\mathrm{x}$ & $\mathrm{x}$ & & $\mathrm{x}$ & \\
\hline 01-Aug & 7 & $11: 30$ & $12: 13$ & $\mathrm{x}$ & $\mathrm{x}$ & $\mathrm{x}$ & & $\mathrm{x}$ & \\
\hline 01-Aug & 8 & $12: 35$ & $13: 16$ & $\mathrm{x}$ & $\mathrm{x}$ & $\mathrm{x}$ & & & $\mathrm{x}$ \\
\hline 01-Aug & 9 & $14: 00$ & $15: 20$ & $\mathrm{x}$ & $\mathrm{x}$ & $\mathrm{x}$ & $\mathrm{x}$ & & \\
\hline 01-Aug & 10 & $15: 54$ & $16: 43$ & $\mathrm{x}$ & $\mathrm{x}$ & $\mathrm{x}$ & & $\mathrm{x}$ & \\
\hline 05-Aug & 11 & $11: 47$ & $12: 29$ & $\mathrm{x}$ & $\mathrm{x}$ & $\mathrm{x}$ & & & $\mathrm{x}$ \\
\hline 05-Aug & 13 & $13: 36$ & $14: 26$ & $\mathrm{x}$ & $\mathrm{x}$ & $\mathrm{x}$ & $\mathrm{x}$ & & \\
\hline 05-Aug & 14 & $14: 42$ & $15: 29$ & $\mathrm{x}$ & $\mathrm{x}$ & $\mathrm{x}$ & & & $\mathrm{x}$ \\
\hline 06-Aug & 16 & $11: 55$ & $12: 37$ & $\mathrm{x}$ & $\mathrm{x}$ & $\mathrm{x}$ & & & $\mathrm{x}$ \\
\hline 06-Aug & 17 & $13: 51$ & $15: 16$ & $\mathrm{x}$ & $\mathrm{x}$ & $\mathrm{x}$ & $\mathrm{x}$ & & \\
\hline 10-Aug & 19 & $13: 41$ & $14: 10$ & $\mathrm{x}$ & $\mathrm{x}$ & $\mathrm{x}$ & & & $\mathrm{x}$ \\
\hline 10-Aug & 20 & $14: 42$ & $15: 45$ & $\mathrm{x}$ & $\mathrm{x}$ & $\mathrm{x}$ & $\mathrm{x}$ & & \\
\hline 10-Aug & 21 & $16: 00$ & $16: 45$ & $\mathrm{x}$ & $\mathrm{x}$ & $\mathrm{x}$ & & & $\mathrm{x}$ \\
\hline 11-Aug & 23 & $12: 00$ & $12: 47$ & $\mathrm{x}$ & $\mathrm{x}$ & $\mathrm{x}$ & & & $\mathrm{x}$ \\
\hline 11-Aug & 24 & $13: 11$ & $14: 05$ & & $\mathrm{x}$ & $\mathrm{x}$ & $\mathrm{x}$ & & \\
\hline 11-Aug & 25 & $14: 25$ & $15: 10$ & $\mathrm{x}$ & $\mathrm{x}$ & $\mathrm{x}$ & & & $\mathrm{x}$ \\
\hline 11-Aug & 26 & $15: 29$ & $16: 22$ & & $\mathrm{x}$ & $\mathrm{x}$ & $\mathrm{x}$ & & \\
\hline 11-Aug & 27 & $16: 58$ & $17: 33$ & & $\mathrm{x}$ & $\mathrm{x}$ & & $\mathrm{x}$ & \\
\hline 15-Aug & 29 & $12: 19$ & $13: 03$ & $\mathrm{x}$ & $\mathrm{x}$ & $\mathrm{x}$ & & $\mathrm{x}$ & \\
\hline 15-Aug & 30 & $13: 46$ & $14: 31$ & & $\mathrm{x}$ & $\mathrm{x}$ & $\mathrm{x}$ & & \\
\hline 15-Aug & 31 & $15: 08$ & $16: 14$ & $\mathrm{x}$ & $\mathrm{x}$ & $\mathrm{x}$ & & & $\mathrm{x}$ \\
\hline 16-Aug & 32 & $12: 30$ & $13: 20$ & $\mathrm{x}$ & $\mathrm{x}$ & $\mathrm{x}$ & & $\mathrm{x}$ & \\
\hline 16-Aug & 33 & $13: 40$ & $14: 00$ & $\mathrm{x}$ & $\mathrm{x}$ & $\mathrm{x}$ & & $\mathrm{x}$ & \\
\hline 17-Aug & 34 & $11: 30$ & $12: 24$ & $\mathrm{x}$ & $\mathrm{x}$ & $\mathrm{x}$ & & & $\mathrm{x}$ \\
\hline 17-Aug & 35 & $13: 45$ & $14: 34$ & $\mathrm{x}$ & $\mathrm{x}$ & $\mathrm{x}$ & & $\mathrm{x}$ & \\
\hline 21-Aug & 36 & $12: 21$ & $13: 12$ & & $\mathrm{x}$ & $\mathrm{x}$ & & $\mathrm{x}$ & \\
\hline 21-Aug & 37 & $13: 40$ & $14: 25$ & $\mathrm{x}$ & $\mathrm{x}$ & $\mathrm{x}$ & & & $\mathrm{x}$ \\
\hline 21-Aug & 38 & $15: 17$ & $16: 26$ & $\mathrm{x}$ & $\mathrm{x}$ & $\mathrm{x}$ & $\mathrm{x}$ & & \\
\hline 21-Aug & 39 & $16: 53$ & $17: 27$ & $\mathrm{x}$ & $\mathrm{x}$ & $\mathrm{x}$ & & & $\mathrm{x}$ \\
\hline 22-Aug & 40 & $9: 29$ & $10: 12$ & $\mathrm{x}$ & $\mathrm{x}$ & $\mathrm{x}$ & & & $\mathrm{x}$ \\
\hline 22-Aug & 41 & $10: 47$ & $11: 37$ & $\mathrm{x}$ & $\mathrm{x}$ & $\mathrm{x}$ & & $\mathrm{x}$ & \\
\hline 22-Aug & 42 & $12: 52$ & $13: 53$ & $\mathrm{x}$ & $\mathrm{x}$ & $\mathrm{x}$ & $\mathrm{x}$ & & \\
\hline 22-Aug & 43 & $14: 22$ & $14: 59$ & $\mathrm{x}$ & $\mathrm{x}$ & $\mathrm{x}$ & & $\mathrm{x}$ & \\
\hline 27-Aug & 45 & $10: 21$ & $11: 10$ & $\mathrm{x}$ & $\mathrm{x}$ & $\mathrm{x}$ & & $\mathrm{x}$ & \\
\hline 27-Aug & 46 & $11: 27$ & $12: 13$ & $\mathrm{x}$ & $\mathrm{x}$ & $\mathrm{x}$ & & & $\mathrm{x}$ \\
\hline 27-Aug & 47 & $13: 11$ & $13: 45$ & & & $\mathrm{x}$ & & & $\mathrm{x}$ \\
\hline 27-Aug & 48 & $15: 09$ & $15: 23$ & $\mathrm{x}$ & $\mathrm{x}$ & $\mathrm{x}$ & $\mathrm{x}$ & & \\
\hline 27-Aug & 49 & $17: 20$ & $17: 50$ & $\mathrm{x}$ & $\mathrm{x}$ & $\mathrm{x}$ & & $\mathrm{x}$ & \\
\hline 28-Aug & 50 & $14: 25$ & $14: 49$ & $\mathrm{x}$ & $\mathrm{x}$ & $\mathrm{x}$ & & $\mathrm{x}$ & \\
\hline
\end{tabular}




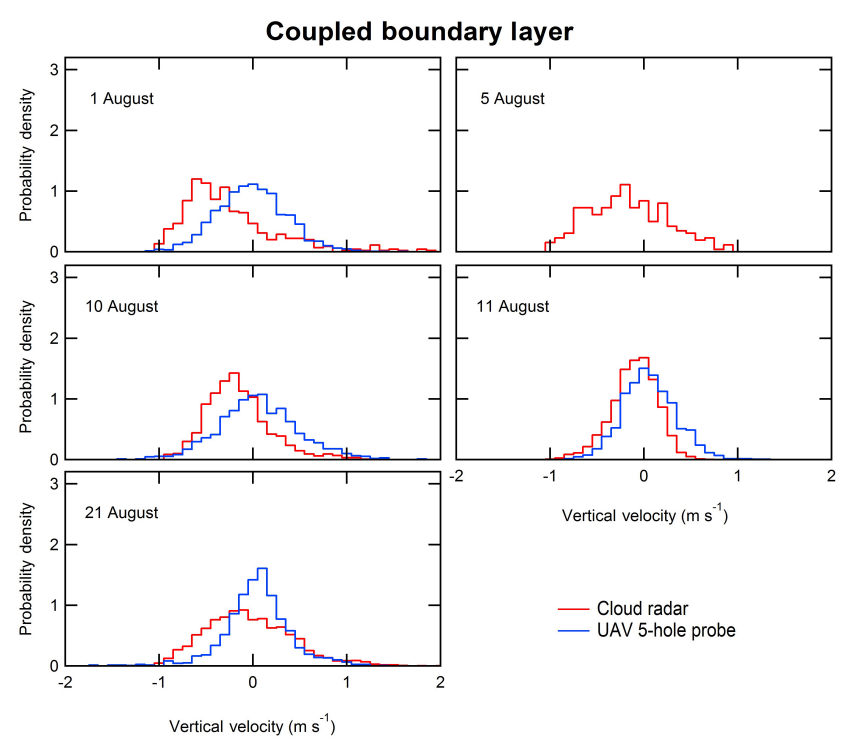

Decoupled boundary layer

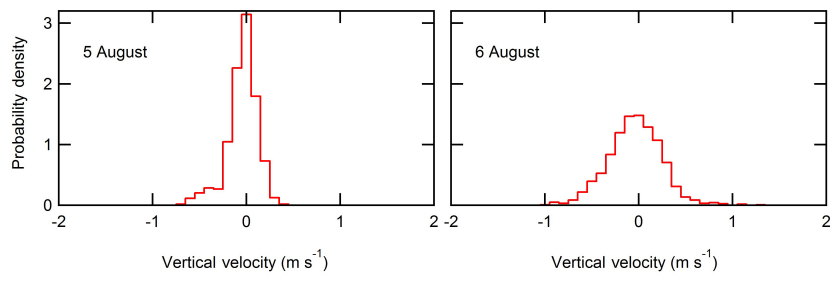

Figure 3. Normalized observed vertical velocity distributions measured by the cloud radar and UAV for each case presented in Table 2.

and $S_{\max }$ are based on methods described by Rosenfeld et al. $(2012,2014,2016)$, which are briefly summarized in the following paragraph. The case selection criteria for satellite observations required the overpass to occur at a zenith angle between 0 and $45^{\circ}$ to the east of the ground track, to have convective development that spans at least $6 \mathrm{~K}$ of cloud temperature from base to top ( $\sim 1 \mathrm{~km}$ thick) and to not precipitate significantly. In situ observations were often of thin clouds $(<1 \mathrm{~km}$ thick), and the satellite observations consist primarily of the more developed clouds in the same system.

To obtain CDNC, cloud droplet effective radius profiles were extracted from the Suomi NPP satellite. Figure 4 shows an image from the Suomi Visible Infrared Imaging Radiometer Suite on 21 August overlapped on a map of western Ireland. The vertical profile in Fig. 4 shows satelliteretrieved and ACPM-simulated effective radius. To estimate the CDNC, the satellite effective radius (Fig. 4) is first converted to mean volume radius $\left(r_{\mathrm{v}}\right)$ using a linear relationship (Freud et al., 2011). Next, it is assumed that any mixing that occurred between the cloud and cloud-free air was inhomogeneous; this implies that the actual $r_{\mathrm{v}}$ is equal to the adiabatic $r_{\mathrm{v}}$. CDNC can be calculated by dividing the adiabatic water content in the cloud by $r_{\mathrm{v}}$ (Rosenfeld et al., 2012; Beals et al., 2015). The cloud-base height and pressure were used to calculate the adiabatic water content. Cloud-base height and pressure were obtained from the height of the NCEP reanalysis of the cloud-base temperature, as retrieved from satellite. The cloud-base height was validated against the ceilometer. Freud et al. (2011) showed that the inhomogeneous assumption resulted in an average overestimate in CDNC of $30 \%$, so the CDNC is reduced by $30 \%$ to account for the bias with the assumption. Finally, to calculate $S_{\max }$, the cloud-base updraft velocity, from the UAV or cloud radar, is needed, and when paired with the CDNC it can be used to empirically calculate $S_{\max }$ (Rosenfeld et al., 2012; Pinsky et al., 2012). The methodology was validated by Rosenfeld et al. (2016).

\subsection{Aerosol-cloud parcel model simulations}

A detailed description of the ACPM is presented in Russell and Seinfeld (1998) and Russell et al. (1999). The ACPM is based on a fixed-sectional approach to represent the (dry) particle size domain, with internally mixed chemical components. Aerosols are generally internally mixed at Mace Head because there are no immediate strong sources of pollution. The model employs a dual-moment (number and mass) algorithm to calculate particle growth from one size section to the next for non-evaporating compounds (namely, all components other than water) using an accommodation coefficient of 1.0 (Raatikainen et al., 2013). The dual-moment method is based on Tzivion et al. (1987) to allow accurate accounting of both aerosol number and mass, and it incorporates independent calculations of the change in particle number and mass for all processes other than growth. The model includes a dynamic scheme for activation of particles to cloud droplets. Liquid water is treated in a moving-section representation, similar to the approach of Jacobson et al. (1994), to account for evaporation and condensation of water in conditions of varying humidity. In subsaturated conditions, aerosol particles below the cloud base are considered to be in local equilibrium with water vapor pressure (i.e., relatively humidity $<100 \%)$.

Coagulation, scavenging and deposition of the aerosol were included in the model, but their effects are negligible given the relatively short simulations used here $(<2 \mathrm{~h})$ and low marine total aerosol particle concentrations $\left(<500 \mathrm{~cm}^{3}\right.$; $D_{\mathrm{p}}>10 \mathrm{~nm}$ ). Feingold et al. (2013) showed that autoconversion and accretion rates are negligible for the simulated values of liquid water content (LWC) and CDNC except for the $\mathrm{C} 21 \mathrm{Cu}$ case, which had $\mathrm{LWC}>1 \mathrm{~g} \mathrm{~m}^{-3}$. Thus, droplet number loss by collision coalescence can be neglected for all cases except for the $\mathrm{C} 21 \mathrm{Cu}$ case. Aerosol hygroscopicity as a function of size (and supersaturation) is determined from $\mathrm{CCN}$ spectra and aerosol size distributions as mentioned in Sect. 3.1, and it is used as model input. The ACPM is also constrained by measured temperature profiles, cloudbase height and updraft velocity distribution (Fig. 3). The incloud lapse rate is assumed to be adiabatic unless specified otherwise, so simulation results represent an upper bound on 
(a)

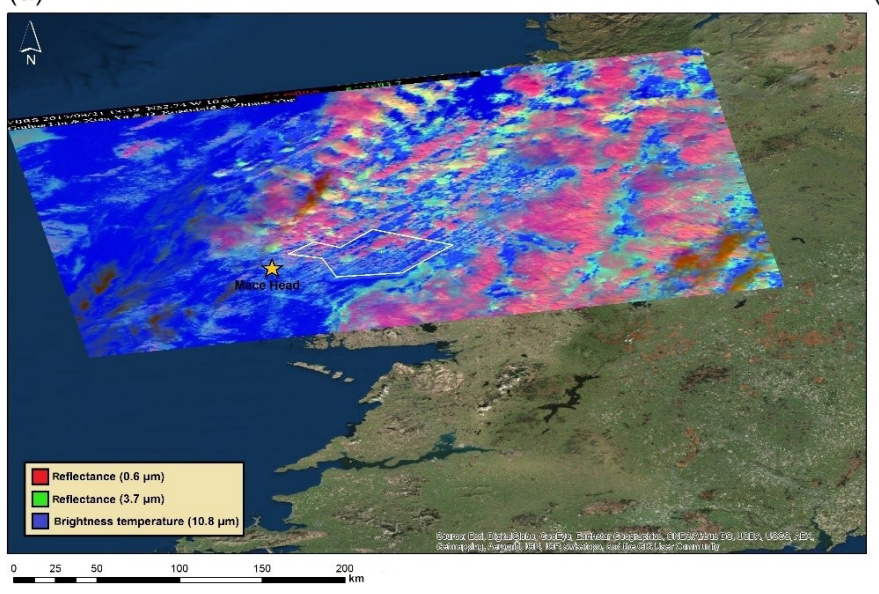

(b)

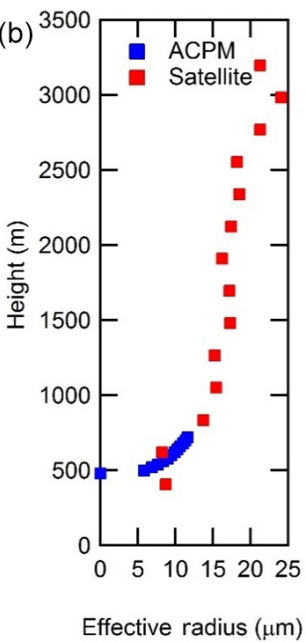

Figure 4. Suomi NPP satellite RGB composite image for 21 August 2015 (a). Mace Head Atmospheric Research Station and UAV flight location are indicated by the yellow star. The white polygon represents the zone for retrieving cloud properties - which is represented by the profile of cloud effective radius (b). Effective radius profiles are presented for both the Suomi NPP satellite (red) and the ACPM (blue).

CDNC and LWC that is unaffected by entrainment. To account for release of latent heat in the cloud, the vertical temperature gradient is calculated as $\mathrm{d} T=-\left(g w \mathrm{~d} t+L \mathrm{~d} q_{1}\right) / c_{p}$, where $\mathrm{d} T$ is change in temperature for the vertical displacement of an air parcel, $g$ is acceleration due to gravity, $w$ is updraft velocity at cloud base, $\mathrm{d} t$ is time step, $L$ is latent heat of water condensation, $q_{1}$ is liquid water mixing ratio and $c_{p}$ is specific heat of water (Bahadur et al., 2012). A weighted ensemble of positive updraft velocities measured with the cloud radar and UAV five-hole probe were applied to the ACPM (Sanchez et al., 2016).

The simulated cloud droplet size distribution is used to calculate the shortwave cloud extinction. Cloud extinction is proportional to the total droplet surface area (Hansen and Travis, 1974; Stephens, 1978) and is calculated from

$\sigma_{\mathrm{ext}}=\int_{0}^{\infty} Q_{\mathrm{ext}}(r) \pi r^{2} n(r) \mathrm{d} r$,

where $r$ is the radius of the cloud droplet; $n(r)$ is the number of cloud droplets with a radius of $r$; and $Q_{\text {ext }}(r)$ is the Mie efficiency factor, which asymptotically approaches 2 for water droplets at large sizes $(r>2 \mu \mathrm{m})$.

Finally, the shortwave radiative flux (RF) is calculated as $\mathrm{RF}=\alpha Q$, where $Q$ is the daily-average insolation at Mace Head and $\alpha$ is the cloud albedo. $\alpha$ is estimated using the following equation (Geresdi et al., 2006; Bohren and Battan, 1980):

$\alpha=\frac{(\sqrt{3}(1-g) \tau)}{(2+\sqrt{3}(1-g) \tau)}$, where $\tau$ is the cloud optical depth defined as

$\tau=\int_{0}^{H} \sigma_{\text {ext }}(h) \mathrm{d} h ;$

$H$ is the cloud height or thickness; and $g$, the asymmetric scattering parameter, is approximated as 0.85 based on Mie scattering calculations for supermicron cloud drops. RF is calculated for both simulated cloud extinction and measured UAV extinction.

\section{Results/discussion}

\subsection{Closure of CDNC and cloud-top shortwave radiative flux}

For this study, closure is defined as the agreement between observations and model simulations of CDNC and cloudtop shortwave radiative flux. In situ measurements of clouds were made by UAVs on 13 days during the campaign. Of these, a subset of six are chosen here for further analysis, which includes comparison with satellite CDNC as well as simulation of cloud properties with the ACPM (Table 2). The remaining days with UAV measurements did not contain sufficient cloud measurements for analysis. A satellite overpass occurred on each of the 6 days; however only 4 of the days contained clouds that were thick enough to analyze with the satellite. The 10 August case experienced a light drizzle, so ACPM simulations were not conducted for this case; however analysis with satellite imagery was still conducted. On 5 August, two cloud layers were examined, for a total of seven case studies shown in Table 2. Aerosols were occasionally influenced by anthropogenic sources; however, the 
Table 2. UAV observations of cloud heights and temperatures and cloud property estimates based on ground measurements. Ground-based Hoppel minimum diameter $\left(D_{\min }\right)$ is used to estimate CDNC. ACPM simulation and satellite results are also presented, as well as differences between simulated and observation-derived cloud-top extinction and cloud-top radiative flux. Case abbreviations include if they are coupled (C) or decoupled (D); the day of the month; and cloud type: cumulus (Cu) or stratocumulus (Sc).

\begin{tabular}{|c|c|c|c|c|c|c|c|}
\hline & \multicolumn{5}{|c|}{ Coupled BL } & \multicolumn{2}{|c|}{ Decoupled BL } \\
\hline & $\begin{array}{r}01 \text { Aug } \\
\text { Cumulus } \\
(\mathrm{C} 01 \mathrm{Cu})^{\mathrm{a}}\end{array}$ & $\begin{array}{r}05 \text { Aug } \\
\text { Cumulus } \\
(\mathrm{C} 05 \mathrm{Cu})\end{array}$ & $\begin{array}{l}10 \text { Aug }^{\mathrm{b}} \\
\text { Cumulus } \\
(\mathrm{C} 10 \mathrm{Cu})\end{array}$ & $\begin{array}{l}11 \mathrm{Aug}^{\mathrm{c}} \\
\mathrm{StratoCu} \\
(\mathrm{C} 11 \mathrm{Sc})\end{array}$ & $\begin{array}{l}21 \text { Aug }^{\mathbf{d}} \\
\text { Cumulus } \\
(\mathrm{C} 21 \mathrm{Cu})\end{array}$ & $\begin{array}{l}05 \mathrm{Aug}^{\mathrm{c}} \\
\text { StratoCu } \\
(\mathrm{D} 05 \mathrm{Sc})\end{array}$ & $\begin{array}{r}06 \text { Aug } \\
\text { Cumulus } \\
(\mathrm{D} 06 \mathrm{Cu})\end{array}$ \\
\hline & \multicolumn{7}{|c|}{ In situ ground-based and UAV measurements } \\
\hline Cloud-base height (m) & 800 & 430 & 650 & 1200 & 460 & 1490 & 2180 \\
\hline Cloud-base temperature $\left({ }^{\circ} \mathrm{C}\right)$ & $7.4 \pm 0.1$ & $10.6 \pm 0.2$ & $8.1 \pm 0.1$ & $3.7 \pm 0.1$ & $10.4 \pm 0.1$ & $6.5 \pm 0.2$ & $-2.1 \pm 0.2$ \\
\hline Cloud-top height (m) & 1040 & 710 & 1720 & 1460 & 960 & 1630 & 2400 \\
\hline Cloud-top temperature $\left({ }^{\circ} \mathrm{C}\right)$ & $5.7 \pm 0.1$ & $8.7 \pm 0.2$ & $1.8 \pm 0.1$ & $2.4 \pm 0.2$ & $7.6 \pm 0.1$ & $5.8 \pm 0.2$ & $-3.1 \pm 0.4$ \\
\hline Measured lapse rate in cloud $\left(\mathrm{K} \mathrm{km}^{-1}\right)$ & 5.7 & 6.1 & 5.1 & 4.7 & 6.0 & 4.1 & 6.3 \\
\hline Number of cloud layers & 1 & $2^{\mathrm{g}}$ & 1 & 1 & 1 & $2^{\mathrm{h}}$ & $2^{\mathrm{h}}$ \\
\hline Hoppel $D_{\min }(\mathrm{nm})$ & $74 \pm 6$ & $78 \pm 16$ & $73 \pm 8$ & $83 \pm 7$ & $83 \pm 5$ & $78 \pm 16$ & $80 \pm 9$ \\
\hline Hoppel $D_{\min }$ CDNC (> Hoppel $D_{\min }, \mathrm{cm}^{-3}$ ) & $129 \pm 5$ & $69 \pm 8$ & $105 \pm 11$ & $87 \pm 5$ & $94 \pm 12$ & $69 \pm 8$ & $164 \pm 13$ \\
\hline Measured cloud $\tau$ & - & 11.7 & - & 8.3 & 29.1 & 1.3 & 4.9 \\
\hline \multirow[t]{2}{*}{ Hoppel minimum critical supersaturation $\left(S_{\text {crit }}\right)$} & $0.43 \pm 0.03$ & $0.61 \pm 0.10$ & $0.37 \pm 0.11$ & $0.37 \pm 0.05$ & $0.41 \pm 0.10$ & $0.61 \pm 0.10$ & $0.31 \pm 0.06$ \\
\hline & \multicolumn{7}{|c|}{ ACPM simulation and satellite-derived cloud properties ${ }^{\mathrm{e}}$} \\
\hline Simulated moist adiabatic lapse rate $\left(\mathrm{K} \mathrm{km}^{-1}\right)$ & 5.0 & 4.5 & 4.9 & 5.7 & 4.5 & 5.1 & 6.4 \\
\hline Simulated cloud-top droplet $r_{e}(\mu \mathrm{m})$ & $10.3 \pm 0.1$ & $14.4 \pm 0.3$ & - & $11.3 \pm 0.2$ & $14.2 \pm 0.4$ & $10.0 \pm 0.1$ & $8.2 \pm 0.2$ \\
\hline Simulated cloud $\tau$ & - & $13.2 \pm 1.9$ & - & $18.7 \pm 2.7$ & $42.1 \pm 11.2$ & $4.4 \pm 0.5$ & $9.0 \pm 1.1$ \\
\hline Cloud-top extinction difference $\left(\delta \sigma_{\text {ext }}, \mathrm{km}^{-1}\right)$ & - & $11 \pm 25$ & - & $36 \pm 12$ & $52 \pm 42$ & $37 \pm 6$ & $34 \pm 7$ \\
\hline $\begin{array}{l}\text { Cloud-top shortwave radiative flux } \\
\text { difference }\left(\delta \mathrm{RF}, \mathrm{W} \mathrm{m} \mathrm{m}^{-2}\right)^{\mathrm{f}}\end{array}$ & - & $11 \pm 26$ & - & $48 \pm 11$ & $20 \pm 6$ & $88 \pm 8$ & $74 \pm 12$ \\
\hline Simulated CDNC $\left(\mathrm{cm}^{-3}\right)$ & $135 \pm 16$ & $60 \pm 12$ & $105 \pm 18$ & $88 \pm 12$ & $105 \pm 31$ & $86 \pm 10$ & $171 \pm 17$ \\
\hline Satellite-estimated CDNC $\left(\mathrm{cm}^{-3}\right)$ & 109 & - & 85 & $58(83)^{\mathrm{i}}$ & 104 & - & - \\
\hline Simulated $S_{\max }(\%)$ & $0.45 \pm 0.09$ & $0.45 \pm 0.18$ & $0.36 \pm 0.15$ & $0.36 \pm 0.09$ & $0.40 \pm 0.20$ & $0.76 \pm 0.04$ & $0.33 \pm 0.06$ \\
\hline Satellite-estimated $S_{\max }(\%)$ & 0.34 & - & 0.27 & 0.48 & 0.34 & - & - \\
\hline
\end{tabular}

cases shown consist of aerosol of marine origin with concentrations under $1000 \mathrm{~cm}^{-3}$ (Fig. 1).

\subsubsection{Ground-based measurement closure}

The columns in Table 2 represent the different cases for both clouds that were (a) coupled with and (b) decoupled from the surface BL ("C" and "D", respectively). The first row in Table 2 includes the state of atmospheric mixing, the date, the type of cloud present and the abbreviation used for each case. The top portion of Table 2 consists of in situ airborne measurements; the bottom portion presents ACPM simulation results and their relation to in situ cloud extinction and satellite-retrieved observations. The ground-based in situ measurements in Table 2 include the Hoppel minimum diameter ${ }^{2}\left(D_{\min }\right)$, as well as the aerosol concentration of aerosol with diameters greater than the Hoppel $D_{\text {min }}$ and the inferred in-cloud critical supersaturation $\left(S_{\mathrm{c}}\right.$; Hop-

\footnotetext{
${ }^{2}$ The Hoppel minimum diameter is the diameter with the lowest aerosol concentration between Aitken mode and accumulation mode.
}

pel, 1979). The dry aerosol particles with diameters greater than the Hoppel $D_{\min }$ have undergone cloud processing and are used here to estimate the CDNC. For each of the case study days, Fig. 5 demonstrates the aerosol size distribution measurements, from the SMPS and APS, that are used to find the Hoppel $D_{\min }$ and Hoppel CDNC and used to initialize the ACPM. The Hoppel CDNC is calculated by integrating the SMPS and APS combined size distributions for aerosol sizes greater than Hoppel $D_{\text {min }}$. Figure 6 shows Hoppel-based CDNC estimates are within $30 \%$ of simulated CDNC for the seven cases. The presence of the Hoppel minimum occurs on average at $80 \mathrm{~nm}$ diameter throughout the campaign (Figs. 1b, 5), implying in-cloud supersaturations near $0.25 \%$ using a campaign-averaged hygroscopicity (K) of 0.42 , which is in agreement with $\mathrm{K}$ values observed in the North Atlantic marine planetary boundary layer in Pringle et al. (2010). 


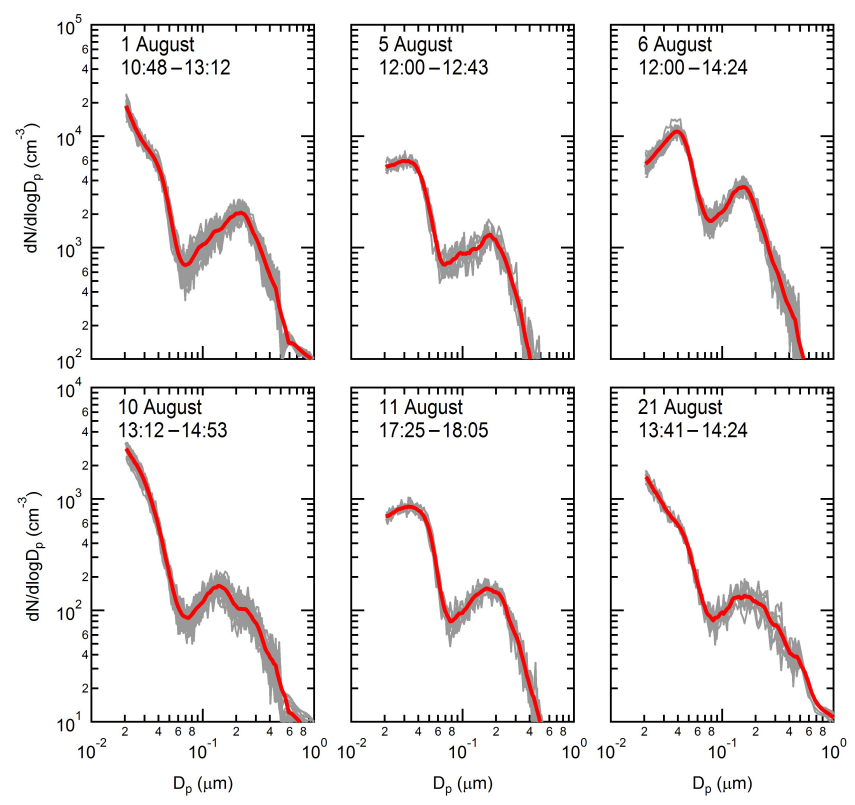

Figure 5. SMPS and APS derived size distributions used for each case study in Table 2. The 5 August size distribution is used for both the coupled and decoupled case. Individual distributions (grey) are from the indicated time ranges in the figure. The time ranges are in UTC. Average distributions are shown in red.

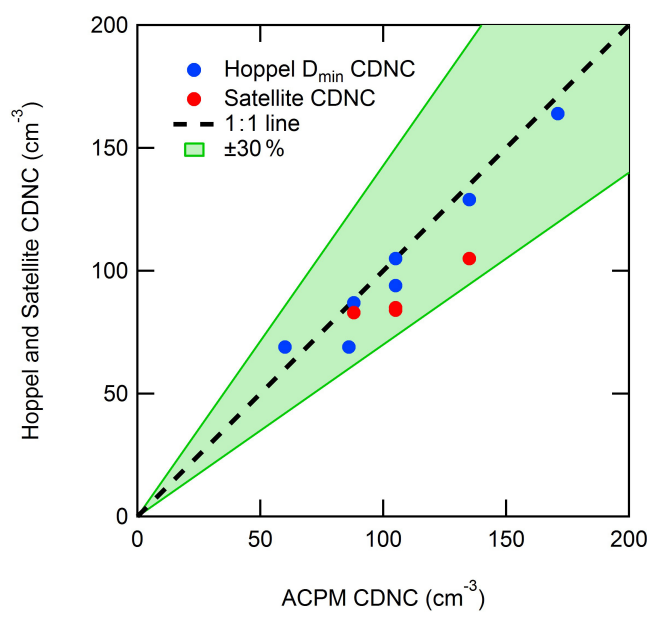

Figure 6. Comparison of simulated CDNC from ACPM with both Hoppel minimum diameter $\left(D_{\min }\right)$ derived CDNC (blue) and satellite-estimated CDNC (red). CDNCs plotted are from the listed cloud cases in Table 2. The green shaded region represents Hoppel and satellite CDNCs within $30 \%$ of ACPM simulation CDNC.

\subsubsection{UAV measurements closure}

Figure 7 displays vertical profiles of meteorological parameters, as well as OPC aerosol number concentration $\left(N_{\mathrm{OPC}}\right.$; $\left.D_{\mathrm{p}}>0.3 \mu \mathrm{m}\right)$ and cloud extinction from two flights (23 and 27 ) on 11 August. The UAV used on flight 23 (conducted between 12:00 and 12:47 UTC) contained the cloud sensor for cloud extinction measurements, and flight 27 (conducted between 16:58 and 17:33 UTC) contained the OPC for droplet size distribution measurements. During this time period the cloud base reduced from $1200 \mathrm{~m}$ on flight 23 to $980 \mathrm{~m}$ on flight 27 , but cloud depth remained approximately the same. In the OPC vertical profiles, in Fig. $7 \mathrm{~d}$, an aerosol layer is shown above the cloud at $\sim 1400 \mathrm{~m}$. OPC measurements are removed inside cloud layers (as aerosol data are contaminated by cloud droplets), hence the gap in OPC data in Fig. 7d. The OPC and temperature measurements, in Fig. 7a and $\mathrm{d}$, are used to show if the boundary layer was coupled (well mixed) or if it was decoupled. The state of the boundary layer and the OPC and temperature measurements are further discussed at the end of this section. The observed temperature and relative humidity profiles, in Fig. 7a and b, are also used to initialize the ACPM. In situ cloud extinction measurements, in Fig. 7c, are then compared to the ACPMsimulated cloud extinction (Fig. 8c).

Figure $8 \mathrm{a}, \mathrm{c}$ and e present the observed and simulated adiabatic cloud extinction profile for three of the case studies $(\mathrm{C} 11 \mathrm{Sc}, \mathrm{D} 05 \mathrm{Sc} \text { and } \mathrm{C} 21 \mathrm{Cu})^{3}$. The measurements are binned into in-cloud, cloud-free and cloud-transition (or cloud-edge) samples. Many clouds had a small horizontal extent, making it difficult for the UAVs to remain in cloud as they ascended and descended in a spiral pattern. Also, high horizontal winds $\left(10-15 \mathrm{~m} \mathrm{~s}^{-1}\right)$ will generally move the cloud outside the field of measurement of the aircraft very quickly. For cases where the UAV did not remain in cloud throughout the ascent or descent, the in-cloud samples are identified as the largest extinction values at each height and are seen in the measurements as a cluster of points (Fig. 8e). Since lateral mixing with cloud-free air exerts an influence near the cloud edges, the cloud-transition air is not representative of the cloud core and adiabatic simulations. The amount of sampling within individual clouds varied from case to case, but the UAVs were generally able to make multiple measurements of the same cloud during each vertical profile. C11Sc was unique in that it involved stratocumulus clouds with a large horizontal extent, allowing the UAV to remain entirely in cloud during the upward and downward vertical profiles around a fixed waypoint. Figure $8 \mathrm{f}$ shows how the difference between simulated and observed extinction $\left(\delta \sigma_{\text {ext }}\right)$ is calculated throughout the cloud based on a discrete sampling of in-cloud measurements. It is not certain that the UAV measured the cloud core for cumulus cases, so $\delta \sigma_{\text {ext }}$ is an upper limit (Table 2).

All ACPM simulation results, including those in Table 2, use the cloud radar updraft velocity as input and not the fivehole probe updraft velocity because five-hole probe updraft velocities are not available for all cases. Nonetheless, the differences in ACPM-simulated shortwave radiative flux between using the five-hole probe and cloud radar updraft ve-

\footnotetext{
${ }^{3} \mathrm{C} / \mathrm{D}$ - coupled/decoupled; $\mathrm{xx}$ - date in August 2015; Sc/Cu stratocumulus/cumulus cloud.
} 


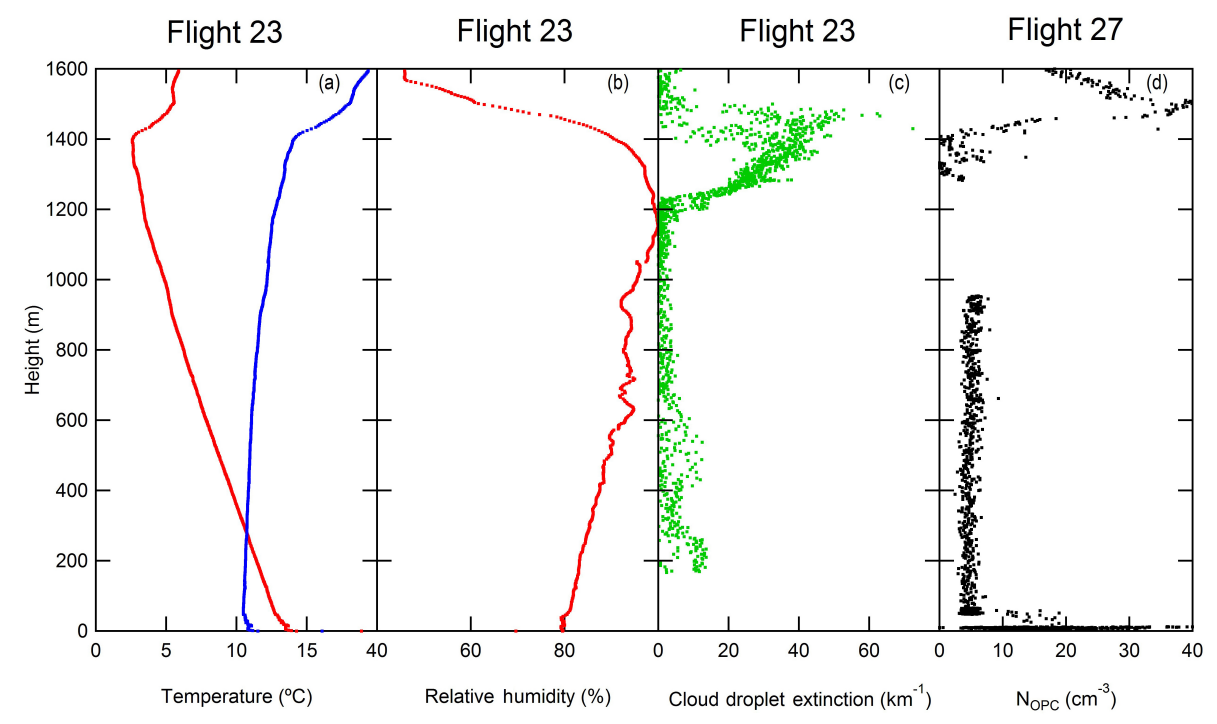

Figure 7. Vertical profiles of temperature, virtual potential temperature $\left(\theta_{\mathrm{V}}\right)$, relative humidity, cloud droplet extinction and OPC total aerosol concentration. The figure consists of measurements collected from flights 23 and 27 on 11 August 2015 at 12:00-12:47 and 16:58-17:33, respectively. The cloud level is $1200-1480 \mathrm{~m}$ in flight 23 and lowered to approximately $980-1280 \mathrm{~m}$ in flight 27 . OPC measurements that occurred in the cloud have been removed.

locities (Fig. 3) is less than $3 \mathrm{~W} \mathrm{~m}^{-2}$ for the four cases that had both measurements.

The integrated effect of $\delta \sigma_{\text {ext }}$ leads to a difference in cloud observed and simulated $\delta$ RF for both clouds that were coupled with and decoupled from the surface boundary layer (Table 2). Figure 9 presents a vertical profile of $N_{\text {OPC }}$ and equivalent potential temperature. OPC measurements within a thin cloud layer at $\sim 2000 \mathrm{~m}$ are removed. $N_{\mathrm{OPC}}$ and equivalent potential temperature $\left(\theta_{\mathrm{e}}\right)$ clearly illustrate this decoupling as shown in an example vertical profile (Fig. 9) at 900 and $2200 \mathrm{~m}$ a.s.l., with the latter representing the inversion between the boundary layer top and free troposphere. $N_{\mathrm{OPC}}$ decreases from an average of 31 to $19 \mathrm{~cm}^{-3}$ at the same altitude as the weak inversion (700-1000 m). In this study, decoupled boundary layers are often observed, and aerosol number concentrations $\left(D_{\mathrm{p}}>0.3 \mu \mathrm{m}\right)$ in the decoupled layer were $44 \% \pm 14 \%$ of those measured at the ground. While $N_{\mathrm{OPC}}$ are not directly representative of CCN concentrations, a reduction in aerosol number with height (and potential differences in hygroscopicity) will nonetheless affect aerosolcloud closures and, ultimately, the cloud radiative properties. Similarly, Norton et al. (2006) showed results from the European Centre for Medium-Range Weather Forecasts (ECMWF) model reanalysis in which surface winds at Mace Head are often decoupled from synoptic flow and, therefore, the air masses in each layer have different origins and most likely different aerosol properties. Consequently, the CCN number concentrations measured at the surface do not represent those in the higher decoupled cloud layer, which ultimately dictates cloud shortwave radiative flux in the region and $\delta \mathrm{RF}$ in Table 2. While aerosol profiles were not collected by UAVs for the decoupled cases presented in Table 2, the $\theta_{\mathrm{e}}$ profiles and ceilometer measurements show evidence of boundary layer decoupling. These two decoupled cases have larger $\delta \sigma_{\text {ext }}$ than the coupled boundary layer cases in this study, leading to larger cloud-top $\delta \mathrm{RF}$ as well. ACPM simulations were conducted using aerosol concentrations based on the approximate average decoupled-to-coupled aerosol concentration ratio (50\%, Fig. 9) to estimate the difference in shortwave radiative flux. For the D05Sc case, simulations with $50 \%$ decreased cloud-base aerosol concentrations show only slight differences in $\delta \mathrm{RF}$ of $2 \mathrm{~W} \mathrm{~m}^{-2}$ and decreases in CDNC of $10 \%$. The decrease in aerosol concentration resulted in increased supersaturation due to the low water uptake from fewer activating droplets. The increased supersaturation caused smaller aerosols to activate (Raatikainen et al., 2013) and, therefore, little change in CDNC. The D05Sc case has very low updraft velocities $\left(0-0.3 \mathrm{~m} \mathrm{~s}^{-1}\right)$. At low updraft velocities, the CDNC is often updraft limited (Reutter et al., 2009). This means the CDNC is very sensitive to the updraft velocities and less sensitive to aerosol concentration. Small errors in updraft velocity and low modeled updraft resolution $\left(0.1 \mathrm{~m} \mathrm{~s}^{-1}\right)$ likely contribute significantly to the error in this case. D06Cu was not influenced as much by low water uptake because the CDNC was much higher at $171 \mathrm{~cm}^{-3}$ than $86 \mathrm{~cm}^{-3}$ for D05Sc. D06Cu the CDNC decreased by $42 \%$, and $\delta \mathrm{RF}$ decreased by $18 \mathrm{~W} \mathrm{~m}^{-2}$. The updraft velocity range for the $\mathrm{D} 06 \mathrm{Cu}$ case is significantly higher than the D05Cu case $\left(0-1.6 \mathrm{~m} \mathrm{~s}^{-1}\right)$. The higher velocities for D05Sc and greater sensitivity to aerosol concentration suggest this case is aerosol limited (Reutter et al., 2009). Both decoupled cases still have a $\delta \mathrm{RF}$ greater than the coupled cases. 

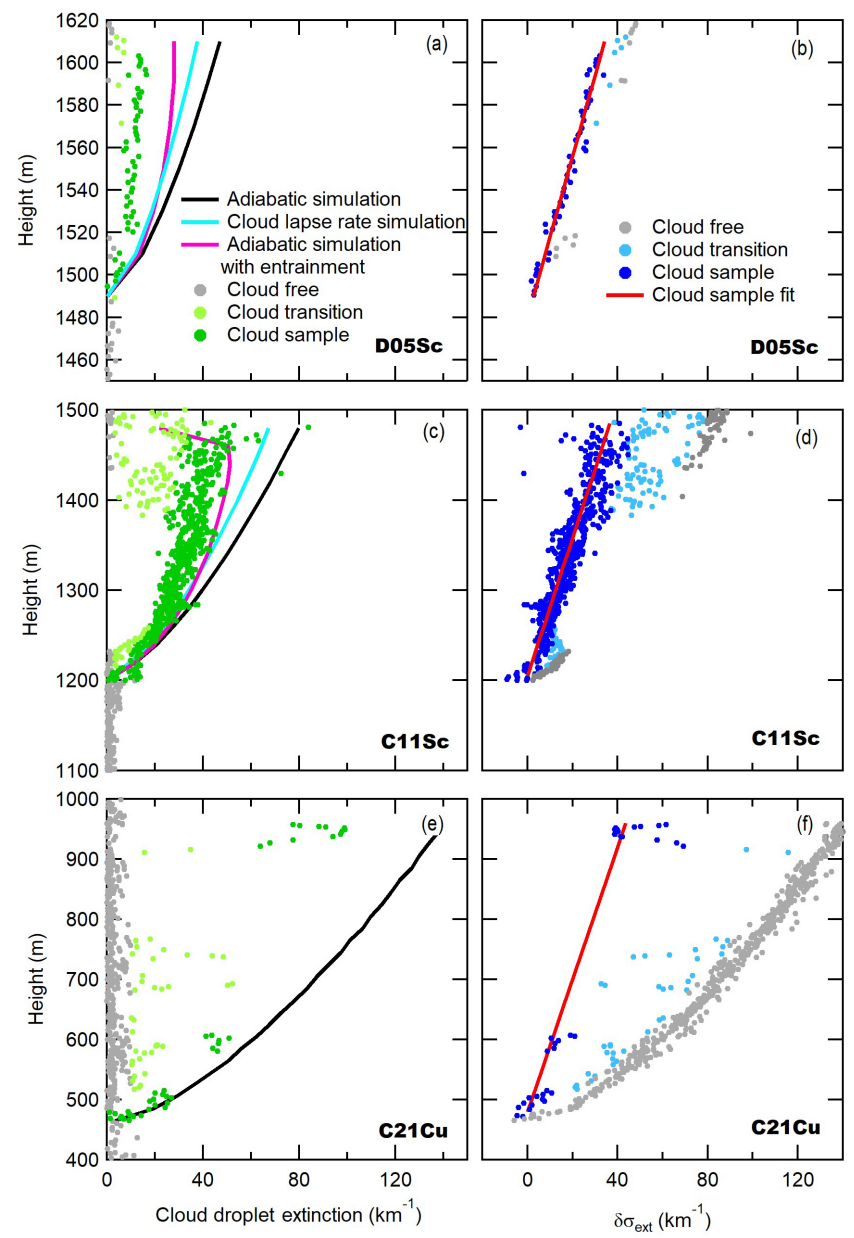

Figure 8. Vertical profiles of measured and simulated cloud extinction from flights D05Sc, C11Sc and $\mathrm{C} 21 \mathrm{Cu}$ (a, $\mathbf{c}$ and e, respectively; Table 2). In situ measurements are classified into cloud, cloud-transition and cloud-free observations. The differences between UAV-observed and ACPM-simulated cloud extinction (black line) in left figures (a, c, e) are used to calculate $\left(\delta \sigma_{\text {ext }}\right)$ as a function of altitude in the right figures $(\mathbf{b}, \mathbf{d}, \mathbf{f})$. The slope of the best fit through in-cloud measurements (red line) represents the increase in $\delta \sigma_{\text {ext }}$ as a function of cloud thickness.

\subsubsection{Satellite measurement closure}

The satellite and simulated CDNC and $S_{\max }$ measurements are presented in the bottom of Table 2. The method for satellite retrieval of cloud properties could not be used for cases when cloud layers were too thin, which unfortunately was the situation during the flights with the decoupled cloud layers. Nonetheless, Fig. 4 shows the satellite image used to identify the clouds to calculate CDNC for C11Sc. Satellite-retrieved cloud-base height and temperature are verified by ground-based ceilometer and temperature measurements. Figure 6 shows the top-down closures, which demonstrate that satellite-estimated CDNC and simulated CDNC are within a $\pm 30 \%$ expected concentrations, which is lim-

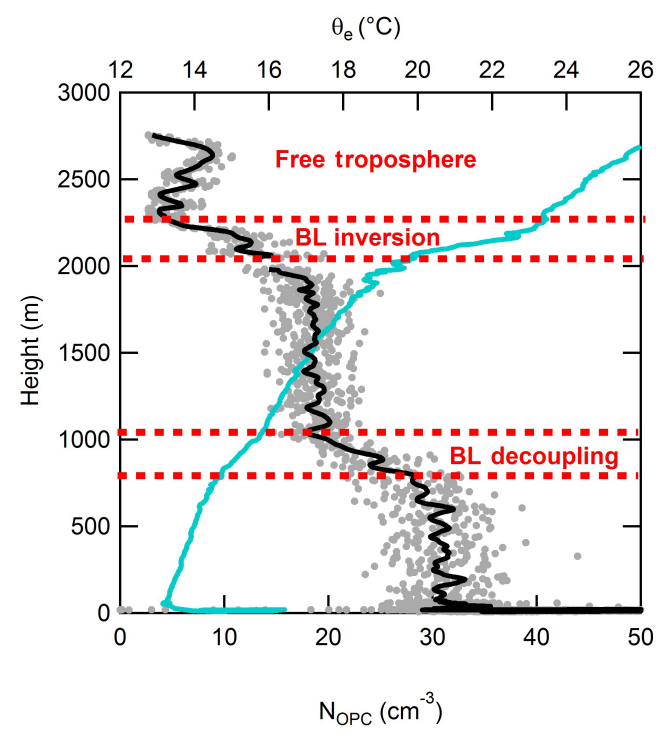

Figure 9. UAV vertical profile of OPC aerosol number concentrations ( $D_{\mathrm{p}}>0.3 \mu \mathrm{m}$; grey) with a $20 \mathrm{~s}$ running mean (black) and equivalent potential temperature $\left(\theta_{\mathrm{e}}\right.$, light blue) illustrate decoupling of the boundary layer. In-cloud OPC measurements (2000$2050 \mathrm{~m}$ ) have been removed.

ited by the retrieval of effective radius (Rosenfeld et al., 2016). The stratocumulus deck at the top of a well-mixed boundary layer $(\mathrm{C} 11 \mathrm{Sc})$ shows evidence of cloud-top inhomogeneous entrainment (see Sect. 3.2). Freud et al. (2011) found that the inhomogeneous mixing assumption used to derive CDNC from satellite measurements resulted in an average overestimate in CDNC of $30 \%$ (considering an adiabatic cloud droplet profile). Consequently, satellite-retrieved CDNC is reduced by $30 \%$ to account for the inhomogeneous entrainment assumption, which does not necessarily reflect the actual magnitude of entrainment in the clouds. For the C11Sc case, before the correction proposed by Freud et al. (2011) is applied, the satellite-derived CDNC $\left(83 \mathrm{~cm}^{-3}\right)$ is within $30 \%$ of the ACPM CDNC $\left(88 \mathrm{~cm}^{-3}\right)$, similar to the other cases (Fig. 6). However, if the correction is applied, the satellite-derived CDNC $\left(58 \mathrm{~cm}^{-3}\right)$ is not within $30 \%$ of the ACPM CDNC. This indicates cloud-top entrainment for the $\mathrm{C} 11 \mathrm{Sc}$ case is already inhomogeneous, and the usual $30 \%$ reduction in CDNC, to correct for the inhomogeneous assumption, should not be applied. Both stratocumulus cases (C11Sc, D05Sc) with cloud-top entrainment (Table 2) are similar to a case studied by Burnet and Brenguier (2007), in which cloud-top entrainment resulted in inhomogeneous mixing. In the following section, C11Sc and D05Sc are reanalyzed to include the effect of cloud-top entrainment on simulated cloud properties using the inhomogeneous mixing assumption. 


\subsection{Entrainment}

Based on the ground-based and UAV measurements, ACPM simulations overestimate cloud shortwave radiative flux significantly for three cases (C11Sc, D05Sc, D06Cu). Section 3.1.2 identified that clouds in decoupled layers (D05Sc, $\mathrm{D} 06 \mathrm{Cu}$ ) have smaller radiative effects than predicted based on ground-based observations as aerosol (and $\mathrm{CCN}$ ) number concentrations in the decoupled layer are often smaller than in the surface mixed layer. In this section, cloud-top entrainment is also shown to influence the radiative properties of two sub-adiabatic stratocumulus clouds, C11Sc and D05Sc.

The UAV observations show that both C11Sc and D05Sc have sub-adiabatic lapse rate measurements, compared to simulated moist-adiabatic lapse rates within the cloud (Table 2). The difference between the observed and simulated lapse rates therefore suggests a source of heating in the cloud. The sub-adiabatic lapse rate is attributed to cloud-top entrainment by downward mixing of warmer air at cloud top. The D06Cu case has a slightly sub-adiabatic observed lapse rate (Table 2); however the difference with respect to an adiabatic lapse rate is within instrument error. For this reason, cloudtop entrainment is not explored for this case, though it may contribute to the error.

Further evidence of cloud-top entrainment is shown through conserved variable mixing diagram analysis. In previous studies, a conserved variable mixing diagram analysis was used to show lateral or cloud-top entrainment by showing linear relationships between observations of conserved variables (Paluch, 1979; Neggers et al., 2002; Burnet and Brenguier, 2007). Paluch (1979) first observed a linear relationship of conservative properties (total water content, $q_{\mathrm{t}}$, and liquid water potential temperature, $\theta_{1}$ ) between cumulus cloud cores and cloud edge, to show the cloud-free source of entrained air. Paluch (1979), Burnet and Brenguier (2007), Roberts et al. (2008) and Lehmann et al. (2009) observed decreases in CDNC and liquid water content in cumulus clouds as a function of distance from the cloud cores that indicate inhomogeneous mixing at the cloud edge. Burnet and Brenguier (2007) also show that $q_{\mathrm{t}}$ is linearly proportional to liquid water potential temperature specifically for a stratocumulus cloud with cloud-top entrainment and inhomogeneous mixing. Direct observations of CDNC and liquid water content were not measured at Mace Head, so direct comparisons of CDNC and $q_{\mathrm{t}}$ with Paluch (1979) and Burnet and Brenguier (2007) cannot be investigated here. However, UAV measurements of cloud extinction (Eq. 1), which are related to CDNC (CDNC $\left.=\int_{0}^{\infty} n(r) \mathrm{d} r\right)$ and liquid water content ( $\mathrm{LWC}=\int_{0}^{\infty} \frac{4}{3} \rho \pi r^{3} n(r) \mathrm{d} r$, where $\rho$ is liquid water density), were measured and are found to be systematically lower than the adiabatic simulated cloud extinction (Fig. 8).

To apply the cloud-top mixing, a fraction of air at cloud base and a fraction of air above cloud top are mixed, conserving $q_{\mathrm{t}}$ and $\theta_{\mathrm{e}}$. The fraction of air from cloud base and cloud top is determined with the measured equivalent poten- tial temperature:

$\theta_{\mathrm{e}, \mathrm{c}}(z)=\theta_{\mathrm{e}, \mathrm{ent}} X(z)+\theta_{\mathrm{e}, \mathrm{CB}}(1-X(z))$,

where $\theta_{\mathrm{e}, \mathrm{c}}(z)$ is the equivalent potential temperature in cloud as a function of height, $\theta_{\mathrm{e}, \text { ent }}$ is the equivalent potential temperature of the cloud-top entrained air, $\theta_{\mathrm{e}, \mathrm{CB}}$ is the equivalent potential temperature of air at cloud base and $X(z)$ is the fraction of cloud-top entrained air as a function of height (referred to as the entrainment fraction). $\theta_{\mathrm{e}, \mathrm{ent}} \theta_{\mathrm{e}, \mathrm{c}}(z)$ and $\theta_{\mathrm{e}, \mathrm{CB}}$ are measured parameters by the UAV and are not affected by latent heating from evaporation or condensation. The equivalent potential temperature, by definition, accounts for the total water content by including the latent heat released by condensing all the water vapor. Equation (4) takes into account latent heating caused by evaporation of droplets. By rearranging Eq. (4), the entrained fraction is calculated as

$X(z)=\frac{\theta_{\mathrm{e}, \mathrm{c}}(z)-\theta_{\mathrm{e}, \mathrm{CB}}}{\theta_{\mathrm{e}, \mathrm{ent}}-\theta_{\mathrm{e}, \mathrm{CB}}}$.

Figure 10a and $\mathrm{b}$ present the relationships between two conservative variables measured by the UAV (water vapor content, $q_{\mathrm{v}}$ and $\theta_{\mathrm{e}}$ ) for C11Sc and D05Sc. The $q_{\mathrm{v}}$ is derived from relative humidity measurements and is equivalent to the $q_{\mathrm{t}}$ for subsaturated, cloud-free air (i.e., $<100 \% \mathrm{RH}$ ). The cloudfree air is shown in blue in Fig. 10, where the below-cloud measurements have lower $\theta_{\mathrm{e}}$ than in cloud and the abovecloud measurements have higher $\theta_{\mathrm{e}}$ than in cloud.

Figure 11 shows the relative humidity and $\theta_{\mathrm{e}}$ profiles used in Fig. 10. For both C11Sc and D05Sc, $\theta_{\mathrm{e}, \mathrm{c}}(\mathrm{z})$ is directly measured in cloud, and $q_{\mathrm{t}}$ and $\theta_{\mathrm{e}}$ exhibit an approximately linear relationship (Fig. 10; Eq. 4). The linear relationship of $q_{\mathrm{t}}$ and $\theta_{\mathrm{e}}$ (between the non-mixed sources of air indicated by orange circles in Fig. 10) is assumed to be a result of the cloud reaching a steady state, with air coming from cloud base and cloud top (e.g., cloud lifetime $\gg$ mixing time). The observed in-cloud $q_{\mathrm{v}}$ in Fig. 10a and $\mathrm{b}$ is less than the conservative variable $q_{\mathrm{t}}$; however, the figure also includes $q_{\mathrm{t}}$ based on simulated adiabatic (marked with an "X") and cloud-top entrainment (dashed black line) conditions. Under adiabatic conditions $q_{\mathrm{t}}$ and $\theta_{\mathrm{e}}$ do not change in the cloud, which is why the adiabatic simulations only consist of one point in Fig. 10. Equation (4) is used to derive the simulated cloud-top entrainment conditions (Fig. 10a and b), where the fraction entrained is used to calculate $q_{\mathrm{v}} t$ and shows a linear relationship between $q_{\mathrm{t}}$ and $\theta_{\mathrm{e}}$. Measurements above cloud top $(\mathrm{RH}<95 \%)$, labeled entrained air, with $q_{\mathrm{v}}>5.1$ and $q_{\mathrm{v}}>6.5 \mathrm{~g} \mathrm{~kg}^{-1}$ are used to represent the properties of the entrained air for C11Sc and D05Sc, respectively (Fig. 10). These conditions were chosen because these values are on the mixing line, between the non-mixed sources identified by the orange circles.

Figure 12 shows the sensitivity of the simulated cloud extinction profile, for the 11 August case, based on measurement uncertainties related to the entrained $q_{\mathrm{t}}$ and $\theta$. The key 
Table 3. Results of the application of entrainment fraction and the measured lapse rate entrainment parameterization for two clouds with observed cloud-top entrainment.

\begin{tabular}{|c|c|c|c|c|}
\hline \multirow[b]{2}{*}{ Entrainment method } & \multicolumn{2}{|c|}{ Coupled BL (C11Sc) } & \multicolumn{2}{|c|}{ Decoupled BL (D05Sc) } \\
\hline & $\begin{array}{r}\text { Homogeneous } \\
\text { mixing } \\
\text { entrainment }\end{array}$ & $\begin{array}{r}\text { Lapse } \\
\text { rate } \\
\text { adjustment }\end{array}$ & $\begin{array}{r}\text { Homogeneous } \\
\text { mixing } \\
\text { entrainment }\end{array}$ & $\begin{array}{r}\text { Lapse } \\
\text { rate } \\
\text { adjustment }\end{array}$ \\
\hline Cloud-top extinction difference $\left(\delta \sigma_{\mathrm{ext}}, \mathrm{km}^{-1}\right)$ & $16 \pm 10$ & $23 \pm 11$ & $16 \pm 5$ & $26 \pm 6$ \\
\hline Simulated cloud $\tau$ & $10.1 \pm 1.5$ & $10.3 \pm 1.6$ & $2.2 \pm 0.3$ & $3.5 \pm 0.5$ \\
\hline Cloud-top shortwave radiative flux difference $\left(\delta \mathrm{RF}, \mathrm{W} \mathrm{m}{ }^{-2}\right)^{\mathrm{a}}$ & $20 \pm 16$ & $32 \pm 17$ & $33 \pm 9$ & $61 \pm 12$ \\
\hline Cloud-base simulated $\mathrm{CDNC}^{\mathrm{b}}$ & $88 \pm 12$ & $83 \pm 12$ & $86 \pm 10$ & $68 \pm 10$ \\
\hline
\end{tabular}

a The difference between the observed (calculated from UAV extinction measurements) and simulated shortwave radiative flux. The error includes the potential error of $\pm 20 \%$ in updraft velocity and the standard error of the CCN concentration measurements. ${ }^{b}$ The simulated CDNC is unchanged at the cloud base for the entrainment fraction method; however the CDNC decreases with height.
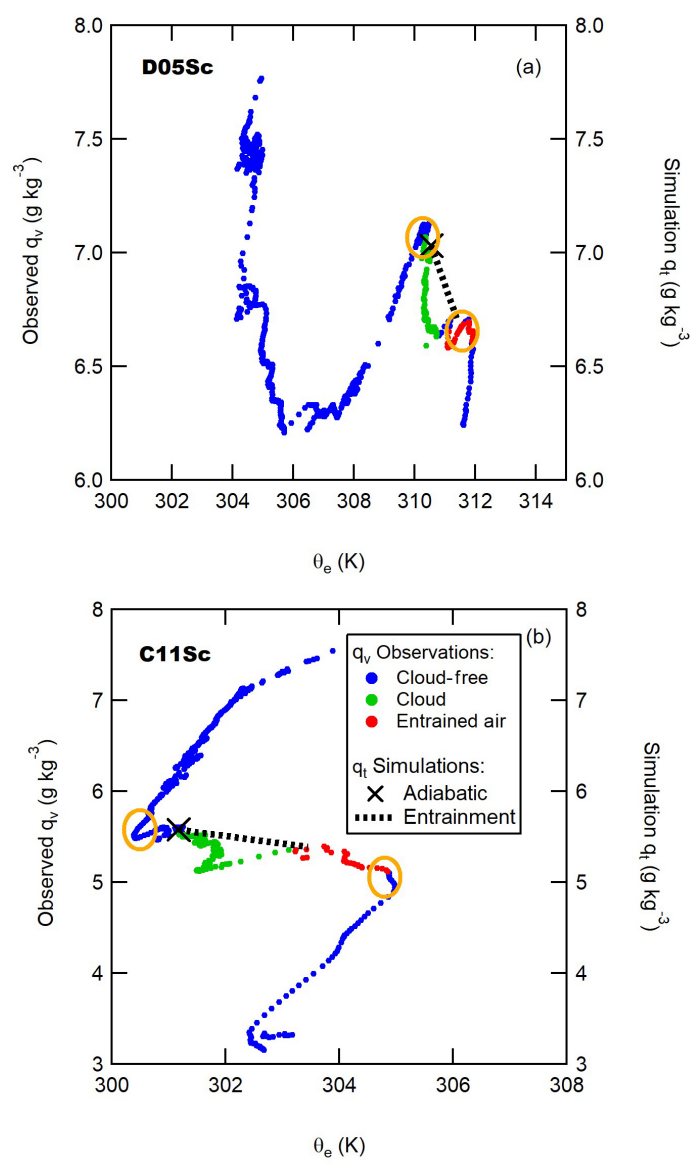

Figure 10. Conservative variables, water vapor content $\left(q_{\mathrm{v}}\right.$, conservative in subsaturated conditions and derived from RH measurements) and equivalent potential temperature $\left(\theta_{\mathrm{e}}\right)$ identify mixing between cloud air and entrained air for flights D06Sc (a) and C11Sc (b). Measurements are defined as cloud-free (blue), in-cloud (green) or entrained-air properties used in simulations (red). The orange circles highlight what is suggested to be the non-mixed sources of air.

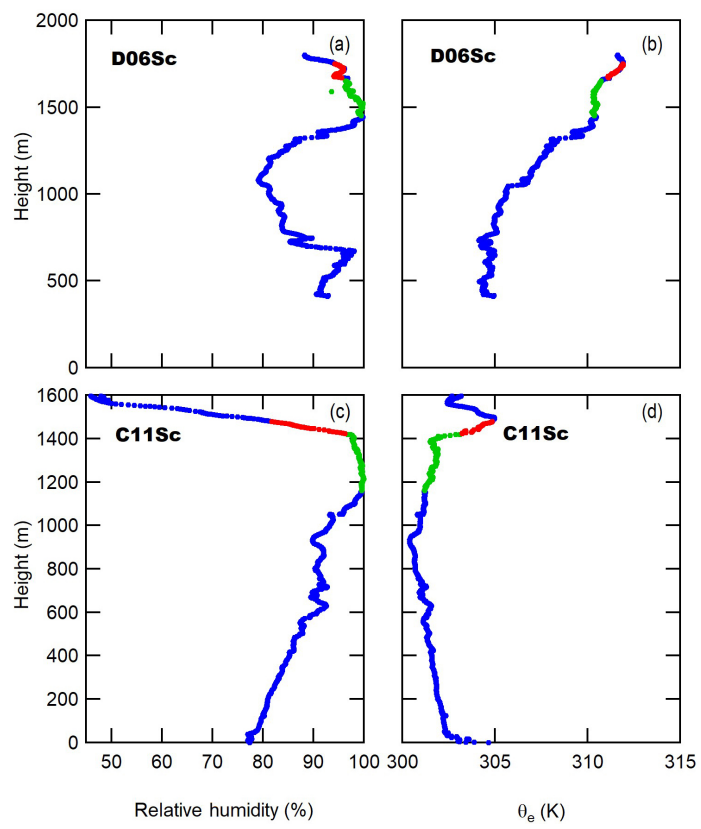

Figure 11. UAV vertical profiles of relative humidity $(\mathbf{a}, \mathbf{c})$ and $\theta_{\mathrm{e}}$ (b, d) for flights D06Sc and C11Sc, used in Fig. 10. Profiles are defined as cloud-free (blue), in-cloud (green) or entrained-air sources (red).

variable for identifying the entrained fraction (Eq. 5), $\theta_{\mathrm{e}, \text { ent }}$, is a function of $q_{\mathrm{t}}$ and $\theta$, so a decrease in either parameter results in a proportional decrease in $\theta_{\mathrm{e}, \text { ent }}$. Equation (5) shows that entrainment fraction becomes more sensitive to the uncertainty related to the measurement of $\theta_{\mathrm{e}}$ as the difference between $\theta_{\mathrm{e}, \text { ent }}$ and $\theta_{\mathrm{e}, \mathrm{CB}}$ approaches zero. This is also shown in Fig. 12, where $\sigma_{\text {ext }}$ is more sensitive to lower entrained $q_{\mathrm{t}}$ and $\theta$ values.

Table 3 shows $\delta \sigma_{\text {ext }}, \delta$ RF and CDNC for two cases with cloud-top entrainment (C11Sc and D05Sc) using two methods of accounting for the cloud-top entrainment. One method (labeled the "inhomogeneous mixing entrainment method" in Table 3) applies the entrainment fraction calculated in 


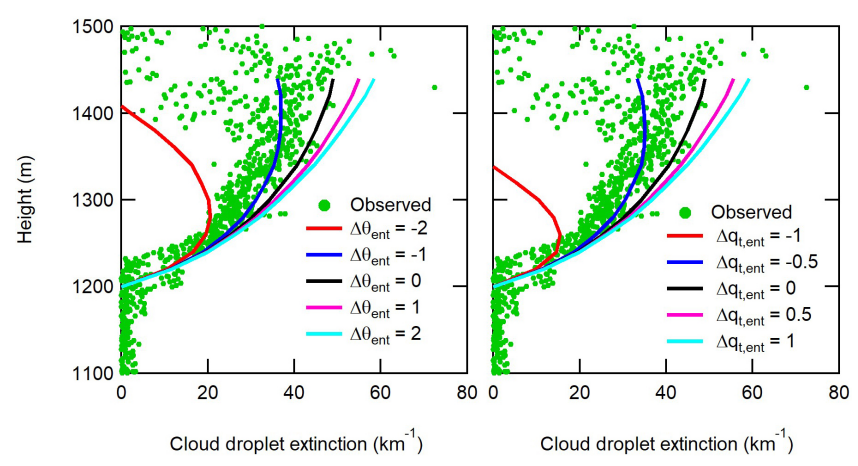

Figure 12. Sensitivity of simulated cloud extinction based on variability of entrained-air potential temperature $\left(\theta_{\mathrm{ent}}, \mathrm{K}\right)$ and entrained-air total water mixing ratio $\left(q_{\mathrm{t}, \mathrm{ent}}, \mathrm{g} \mathrm{kg}^{-1}\right)$ for the $\mathrm{C} 11 \mathrm{Sc}$

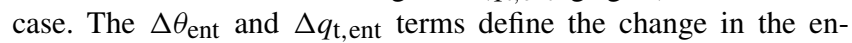
trained $\theta$ and $q_{\mathrm{t}}$ values where no change ( $\Delta \theta_{\mathrm{ent}}=0$ and $\Delta q_{\mathrm{t}, \text { ent }}=0$ ) is equivalent to the adiabatic simulation with entrainment from Fig. 8c.

Eq. (5), and the other an entrainment parameterization presented by Sanchez et al. (2016). The entrainment parameterization constrains the ACPM simulation to use the observed in-cloud lapse rate instead of assuming an adiabatic lapse rate. This is labeled the "lapse rate adjustment" entrainment method in Table 3. In the sub-adiabatic cloud cases (C11Sc and D05Sc), the measured in-cloud lapse rate is lower than the adiabatic lapse rate, which leads to the condensation of less water vapor and subsequent activation of fewer droplets in the ACPM simulation. Similarly, when applying the inhomogeneous mixing entrainment method, the dryer and warmer entrained air (from above cloud top) leads to evaporation of liquid water in the cloud. Previous observations of stratocumulus cloud-top mixing suggest the entrainment is inhomogeneous (Burnet and Brenguier, 2007; Beals et al., 2015), which implies that timescales of evaporation are much less than the timescales of mixing, such that a fraction of the droplets are evaporated completely and the remaining droplets are unaffected by the entrainment. The net decrease in CDNC subsequently results in less extinction of solar radiation compared to the purely adiabatic simulation.

The inclusion of inhomogeneous mixing entrainment improved the ACPM accuracy for both C11Sc and D05Sc using the measured lapse rate and entrainment fraction methods (Fig. 8, Table 3). After accounting for inhomogeneous entrainment, $\delta \mathrm{RF}$ decreased from 88 to 33 and 48 to $20 \mathrm{~W} \mathrm{~m}^{-2}$ for D05Sc and D11Sc, respectively, using the entrainment fraction method. D05Sc simulations still yield significant $\delta \mathrm{RF}$ even after accounting for inhomogeneous mixing entrainment, likely because the cloud is in a decoupled BL, as noted in Sect. 3.1.2 to exhibit lower aerosol concentrations than those measured at the surface. The CDNC presented in Table 3 represents the CDNC at cloud base and did not change after applying the entrainment fraction method; however, the CDNC decreases with height for the entrain- ment fraction method rather than remaining constant with height. Finally, the lapse rate adjustment entrainment method (Sanchez et al., 2016) does improve ACPM accuracy between in situ and satellite-retrieved cloud optical properties relative to the adiabatic simulations but has greater $\delta \sigma_{\text {ext }}$ throughout the cloud than the inhomogeneous mixing entrainment method. For the lapse rate adjustment entrainment method $\delta \mathrm{RF}$ decreased from 88 to 61 and 48 to $32 \mathrm{~W} \mathrm{~m}^{-2}$ for D05Sc and D11Sc, respectively. The lapse rate adjustment entrainment method resulted in lower $\delta \mathrm{RF}$ than the purely adiabatic simulations; however, $\delta \mathrm{RF}$ was minimized by directly accounting for the entrainment fraction.

\section{Conclusions}

This work presents measurements conducted in August 2015 at the Mace Head Atmospheric Research Station in Ireland, from multiple platforms including ground-based, airborne and satellite measurements. As part of the BACCHUS (Impact of Biogenic versus Anthropogenic emissions on Clouds and Climate: towards a Holistic UnderStanding) European collaborative project, the goal of this study is to understand key processes affecting aerosol-cloud shortwave radiative flux interactions. Seven cases including cumulus and stratocumulus clouds were investigated to quantify aerosolcloud interactions using ground-based and airborne measurements (bottom-up closure), as well as cloud microphysical and radiative properties using airborne measurements and satellite retrievals (top-down closure). An aerosol-cloud parcel model was used to link the ground-based, airborne and satellite observations, and to quantify uncertainties related to aerosols, cloud microphysical properties and resulting cloud optical properties.

ACPM simulations represent bottom-up and top-down closures within uncertainties related to satellite retrievals for conditions with a coupled boundary layer and adiabatic cloud development. For these conditions, the difference in shortwave radiative flux between simulations and in situ observed parameters is no greater than $20 \mathrm{~W} \mathrm{~m}^{-2}$. However, when entrainment and decoupling of the cloud layer occur, the ACPM simulations overestimate the cloud shortwave radiative flux. Of the seven cases, two of the observed clouds occurred in a decoupled layer, resulting in differences in observed and simulated $\delta \mathrm{RF}$ of 88 and $74 \mathrm{~W} \mathrm{~m}^{-2}$ for the decoupled stratocumulus case on 5 August (D05Sc) and the decoupled cumulus case on 6 August (D06Cu) cases, respectively. Adiabatic ACPM simulations resulted in a maximum cloud-top $\delta \mathrm{RF}$ value of $20 \mathrm{~W} \mathrm{~m}^{-2}$ for coupled boundary layer cases and $74 \mathrm{~W} \mathrm{~m}^{-2}$ for the decoupled boundary layer cases, after accounting for cloud-top entrainment. The reduction in aerosol concentrations in the decoupled layer compared to ground-based measurements is a factor in overestimating decoupled cloud-top shortwave radiative flux with the ACPM; however simulations with $50 \%$ decreased aerosol concentra- 
tions show only slight differences in $\delta \mathrm{RF}$ of $2 \mathrm{~W} \mathrm{~m}^{-2}$ and decreases in CDNC of $10 \%$ for D05Sc. For D06Cu $\delta$ RF decreased by $18 \mathrm{~W} \mathrm{~m}^{-2}$, and the CDNC decreased by $42 \%$. Even after decreasing the aerosol concentration by 50 , both decoupled cases have $\delta \mathrm{RF}$ values significantly higher than the coupled boundary layer cases $\left(<20 \mathrm{~W} \mathrm{~m}^{-2}\right)$.

For the cases with cloud-top entrainment, D05Sc and the coupled stratocumulus case on 11 August (C11Sc), liquid water content is one of the major factors in overestimating cloud-top shortwave radiative flux with the ACPM. For these cases, the measured in-cloud lapse rates are lower than adiabatic lapse rates, suggesting a source of heat due to entrainment of warmer, drier air from above the cloud. Furthermore, linear relationships between conservative variables (simulated total water vapor, $q_{t}$, and equivalent potential temperature, $\theta_{\mathrm{e}}$ ) also suggest mixing between air at cloud base and cloud top. For D05Sc, after accounting for cloud-top entrainment by applying the entrainment fraction, $\delta \mathrm{RF}$ decreased from 88 to $33 \mathrm{~W} \mathrm{~m}^{-2}$. For the coupled boundary layer case with entrainment $(\mathrm{C} 11 \mathrm{Sc})$ the $\delta \mathrm{RF}$ decreases from 48 to $20 \mathrm{~W} \mathrm{~m}^{-2}$ after accounting for cloud-top entrainment with the entrainment fraction.

Based on airborne observations with UAVs, decoupling of the boundary layer occurred on 4 of the 13 flight days (two decoupled cloud cases were not discussed due to the lack of in-cloud measurements). However, cloud drop entrainment was only observed on 2 of those days, limited by the ability to make in situ measurements. These measurements occurred during the summer, so additional measurements are needed to look at seasonal trends. These cases illustrate the need for in situ observations to quantify entrainment mixing and cloud-base CCN concentrations particularly when the mixing state of the atmosphere is not known. Using groundbased observations to model clouds in decoupled boundary layers and not including cloud-top entrainment are shown to cause significant differences between observations and simulation radiative forcing and, therefore, should be included in large-scale modeling studies to accurately predict future climate forcing.

UAV measurements were coordinated with 13 days of satellite overpasses, and cloud microphysical properties were retrieved for four of the cases. When accounting for entrainment, the differences between simulated and satelliteretrieved CDNC are within the expected $30 \%$ accuracy of the satellite retrievals (Rosenfeld et al., 2016). However, in situ measurements are necessary to refine satellite retrievals to allow cloud properties to be studied on larger spatial scales.

Data availability. All data are available by contacting the corresponding author or through the following link: https://hal-meteofrance.archives-ouvertes.fr/meteo-01567780/ file/MH_data_for_archive.zip.
Competing interests. The authors declare that they have no conflict of interest.

Special issue statement. This article is part of the special issue "BACCHUS - Impact of Biogenic versus Anthropogenic emissions on Clouds and Climate: towards a Holistic UnderStanding (ACP/AMT/GMD inter-journal SI)". It is not associated with a conference.

Acknowledgements. The research leading to these results received funding from the European Union's Seventh Framework Programme (FP7/2007-2013) project BACCHUS under grant agreement no. 603445. EU H2020 project ACTRIS-2 under the grant agreement no. 654109 is also acknowledged for supporting the Mace Head Atmospheric Research Station. Keri Nicoll acknowledges a NERC Independent Research Fellowship (NE/L011514/1). Darius Ceburnis acknowledges the Irish EPA (2012-CCRP-FS.12). Jana Preissler acknowledges the Irish EPA (2015-CCRP-FS.24). Radiance Calmer acknowledges financial support from Météo France. Kevin J. Sanchez acknowledges the Chateaubriand Fellowship. We thank École Nationale de l'Aviation Civile (ENAC) for assistance with construction and operation of the UAVs. The authors also acknowledge Kirsten Fossum for the collection of SMPS data. We applied a sequence-defines-credit approach for the sequence of authorship.

Edited by: Hailong Wang

Reviewed by: four anonymous referees

\section{References}

Albrecht, B. A., Bretherton, C. S., Johnson, D., Scubert, W. H., and Frisch, A. S.: The Atlantic Stratocumulus Transition Experiment - ASTEX, B. Am. Meteorol. Soc., 76, 889-904, https://doi.org/10.1175/15200477(1995)076<0889:TASTE >2.0.CO;2, 1995.

Bahadur, R., Russell, L. M., Jacobson, M. Z., Prather, K. Nenes, A., Adams, P., and Seinfeld, J. H.: Importance of composition and hygroscopicity of $\mathrm{BC}$ particles to the effect of $\mathrm{BC}$ mitigation on cloud properties: Application to California conditions, J. Geophys. Res.-Atmos., 117, D09204, https://doi.org/10.1029/2011jd017265, 2012.

Bates, T. S., Huebert, B. J., Gras, J. L., Griffiths, F. B., and Durkee, P. A.: International Global Atmospheric Chemistry (IGAC) project's first aerosol characterization experiment (ACE 1): Overview, J. Geophys. Res.-Atmos., 103, 16297-16318, https://doi.org/10.1029/97jd03741, 1998.

Beals, M. J., Fugal, J. P., Shaw, R. A., Lu, J., Spuler, S. M., and Stith, J. L.: Holographic measurements of inhomogeneous cloud mixing at the centimeter scale, Science, 350, 87-90, https://doi.org/10.1126/science.aab0751, 2015.

Bohren, C. F. and Battan, L. J.: Radar Backscattering by Inhomogeneous Precipitation Particles, J. Atmos. Sci., 37, 1821-1827, https://doi.org/10.1175/15200469(1980)037<1821:RBBIPP>2.0.CO;2, 1980. 
Bretherton, C. S. and Wyant, M. C.: Moisture transport, lower tropospheric stability and decoupling of cloud-topped boundary layers, J. Atmos. Sci., $\quad 54, \quad 148-167, \quad$ https://doi.org/10.1175/15200469(1997)054<0148:MTLTSA>2.0.CO;2, 1997.

Burnet, F. and Brenguier, J.-L.: Observational study of the entrainment-mixing process in warm convective clouds, J. Atmos. Sci., 64, 1995-2011, https://doi.org/10.1175/jas3928.1, 2007.

Calmer, R., Roberts, G., Preissler, J., Derrien, S., and O’Dowd, C.: 3D Wind Vector Measurements using a 5-hole Probe with Remotely Piloted Aircraft, Atmos. Meas. Tech. Discuss., https://doi.org/10.5194/amt-2017-233, in review, 2017.

Coe, H., Allan, J. D., Alfarra, M. R., Bower, K. N., Flynn, M. J., McFiggans, G. B., Topping, D. O., Williams, P. I., O’Dowd, C. D., Dall'Osto, M., Beddows, D. C. S., and Harrison, R. M.: Chemical and physical characteristics of aerosol particles at a remote coastal location, Mace Head, Ireland, during NAMBLEX, Atmos. Chem. Phys., 6, 3289-3301, https://doi.org/10.5194/acp-63289-2006, 2006.

Conant, W. C., VanReken, T. M., Rissman, T. A., Varutbangkul, V., Jonsson, H. H., Nenes, A., Jimenez, J. L., Delia, A. E., Bahreini, R., Roberts, G. C., Flagan, R. C., and Seinfeld, J. H.: Aerosol-cloud drop concentration closure in warm cumulus, J. Geophys. Res.-Atmos., 109, D13204, https://doi.org/10.1029/2003jd004324, 2004.

Dall'Osto, M., Ceburnis, D., Martucci, G., Bialek, J., Dupuy, R., Jennings, S. G., Berresheim, H., Wenger, J., Healy, R., Facchini, M. C., Rinaldi, M., Giulianelli, L., Finessi, E., Worsnop, D., Ehn, M., Mikkilä, J., Kulmala, M., and O'Dowd, C. D.: Aerosol properties associated with air masses arriving into the North East Atlantic during the 2008 Mace Head EUCAARI intensive observing period: an overview, Atmos. Chem. Phys., 10, 8413-8435, https://doi.org/10.5194/acp-10-8413-2010, 2010.

Feingold, G., McComiskey, A., Rosenfeld, D., and Sorooshian, A.: On the relationship between cloud contact time and precipitation susceptibility to aerosol, J. Geophys. Res.-Atmos., 118, 1054410554, https://doi.org/10.1002/jgrd.50819, 2013.

Fountoukis, C., Nenes, A., Meskhidze, N., Bahreini, R., Conant, W. C., Jonsson, H., Murphy, S., Sorooshian, A., Varutbangkul, V., Brechtel, F., Flagan, R. C., and Seinfeld, J. H.: Aerosol-cloud drop concentration closure for clouds sampled during the International Consortium for Atmospheric Research on Transport and Transformation 2004 campaign, J. Geophys. Res.-Atmos., 112, D10S30, https://doi.org/10.1029/2006jd007272, 2007.

Freud, E., Rosenfeld, D., and Kulkarni, J. R.: Resolving both entrainment-mixing and number of activated $\mathrm{CCN}$ in deep convective clouds, Atmos. Chem. Phys., 11, 12887-12900, https://doi.org/10.5194/acp-11-12887-2011, 2011.

Geresdi, I., Meszaros, E., and Molnar, A.: The effect of chemical composition and size distribution of aerosol particles on droplet formation and albedo of stratocumulus clouds, Atmos. Environ., 40, 1845-1855, https://doi.org/10.1016/j.atmosenv.2005.11.012, 2006.

Goersdorf, U., Lehmann, V., Bauer-Pfundstein, M., Peters, G., Vavriv, D., Vinogradov, V., and Volkov, V.: A 35-GHz Polarimetric Doppler Radar for Long-Term Observations of Cloud Parameters-Description of System and Data Processing, J. At- mos. Ocean. Tech., 32, 675-690, https://doi.org/10.1175/jtech-d14-00066.1, 2015.

Hansen, J. E. and Travis, L. D.: Light-Scattering in Planetary Atmospheres, Space Sci. Rev., 16, 527-610, https://doi.org/10.1007/bf00168069, 1974.

Harrison, R. G. and Nicoll, K. A.: Note: Active optical detection of cloud from a balloon platform, Rev. Sci. Instrum., 85, 066104, https://doi.org/10.1063/1.4882318, 2014.

Heard, D. E., Read, K. A., Methven, J., Al-Haider, S., Bloss, W. J., Johnson, G. P., Pilling, M. J., Seakins, P. W., Smith, S. C., Sommariva, R., Stanton, J. C., Still, T. J., Ingham, T., Brooks, B., De Leeuw, G., Jackson, A. V., McQuaid, J. B., Morgan, R., Smith, M. H., Carpenter, L. J., Carslaw, N., Hamilton, J., Hopkins, J. R., Lee, J. D., Lewis, A. C., Purvis, R. M., Wevill, D. J., Brough, N., Green, T., Mills, G., Penkett, S. A., Plane, J. M. C., Saiz-Lopez, A., Worton, D., Monks, P. S., Fleming, Z., Rickard, A. R., Alfarra, M. R., Allan, J. D., Bower, K., Coe, H., Cubison, M., Flynn, M., McFiggans, G., Gallagher, M., Norton, E. G., O’Dowd, C. D., Shillito, J., Topping, D., Vaughan, G., Williams, P., Bitter, M., Ball, S. M., Jones, R. L., Povey, I. M., O’Doherty, S., Simmonds, P. G., Allen, A., Kinnersley, R. P., Beddows, D. C. S., Dall'Osto, M., Harrison, R. M., Donovan, R. J., Heal, M. R., J ennings, S. G., Noone, C., and Spain, G.: The North Atlantic Marine Boundary Layer Experiment(NAMBLEX), Overview of the campaign held at Mace Head, Ireland, in summer 2002, Atmos. Chem. Phys., 6, 2241-2272, https://doi.org/10.5194/acp-6-22412006, 2006.

Heese, B., Flentje, H., Althausen, D., Ansmann, A., and Frey, S.: Ceilometer lidar comparison: backscatter coefficient retrieval and signal-to-noise ratio determination, Atmos. Meas. Tech., 3, 1763-1770, https://doi.org/10.5194/amt-3-1763-2010, 2010.

Hoppel, W. A.: Measurement of the size distribution and ccn supersaturation spectrum of sub-micron aerosols over the ocean, J. Atmos. Sci., 36, 2006-2015, https://doi.org/10.1175/15200469(1979)036<2006:motsda>2.0.co;2, 1979.

Jacobson, M. Z., Turco, R. P., Jensen, E. J., and Toon, O. B.: Modeling Coagulation Among Particles of Different Composition and Size, Atmos. Environ., 28, 1327-1338, https://doi.org/10.1016/1352-2310(94)90280-1, 1994.

Jones, C. R., Bretherton, C. S., and Leon, D.: Coupled vs. decoupled boundary layers in VOCALS-REx, Atmos. Chem. Phys., 11, 7143-7153, https://doi.org/10.5194/acp-11-7143-2011, 2011.

Kleefeld, C., O'Dowd, C. D., O'Reilly, S., Jennings, S. G., Aalto, P., Becker, E., Kunz, G., and de Leeuw, G.: Relative contribution of submicron and supermicron particles to aerosol light scattering in the marine boundary layer, J. Geophys. Res.-Atmos., 107, 8103, https://doi.org/10.1029/2000jd000262, 2002.

Kunz, G. J., de Leeuw, G., Becker, E., and O'Dowd, C. D.: Lidar observations of atmospheric boundary layer structure and sea spray aerosol plumes generation and transport at Mace Head, Ireland (PARFORCE experiment), J. Geophys. Res.-Atmos., 107, 8106, https://doi.org/10.1029/2001jd001240, 2002.

Lehmann, K., Siebert, H., and Shaw, R. A.: Homogeneous and Inhomogeneous Mixing in Cumulus Clouds: Dependence on Local Turbulence Structure, J. Atmos. Sci., 66, 3641-3659, https://doi.org/10.1175/2009jas3012.1, 2009.

Lenschow, D. H. and Spyers-Duran, P.: Measurement Techniques: Air Motion Sensing, NCAR, 1989. 
Lilly, D. K.: Models of cloud-topped mixed layers under a strong inversion, Q. J. Roy. Meteor. Soc., 94, 292-309, https://doi.org/10.1002/qj.49709440106, 1968.

Martucci, G., Milroy, C., and O'Dowd, C. D.: Detection of Cloud-Base Height Using Jenoptik CHM15K and Vaisala CL31 Ceilometers, J. Atmos. Ocean. Tech., 27, 305-318, https://doi.org/10.1175/2009jtecha1326.1, 2010.

Melchionna, S., Bauer, M., and Peters, G.: A new algorithm for the extraction of cloud parameters using multipeak analysis of cloud radar data - First application and preliminary results, Meteorol. Z., 17, 613-620, https://doi.org/10.1127/0941-2948/2008/0322, 2008.

Milroy, C., Martucci, G., Lolli, S., Loaec, S., Sauvage, L., Xueref-Remy, I., Lavric, J. V., Ciais, P., Feist, D. G., Biavati, G., and O'Dowd, C. D.: An Assessment of PseudoOperational Ground-Based Light Detection and Ranging Sensors to Determine the Boundary-Layer Structure in the Coastal Atmosphere, Advances in Meteorology, 2012, 929080, https://doi.org/10.1155/2012/929080, 2012.

Neggers, R. A. J., Duynkerke, P. G., Rodts, S. M. A., and Ams, A. M. S.: Shallow cumulus convection: a validation of largeeddy simulation against aircraft and Landsat observations, 15th Symposium on Boundary Layers and Turbulence, 199-202, https://doi.org/10.1256/qj.02.93, 2002.

Nicholls, S. and Leighton, J.: An Observational Study of the Structure of Stratiform Cloud Sheets, 1. Structure, Q. J. Roy. Meteor. Soc., 112, 431-460, https://doi.org/10.1002/qj.49711247209, 1986.

Nicoll, K., Harrison, R. G., and Brus, D.: Optical cloud detection from a disposable airborne sensor, EGU General Assembly, Vienna Austria, 2016.

Norton, E. G., Vaughan, G., Methven, J., Coe, H., Brooks, B., Gallagher, M., and Longley, I.: Boundary layer structure and decoupling from synoptic scale flow during NAMBLEX, Atmos. Chem. Phys., 6, 433-445, https://doi.org/10.5194/acp-6433-2006, 2006.

O'Connor, T. C., Jennings, S. G., and O'Dowd, C. D.: Highlights of fifty years of atmospheric aerosol research at Mace Head, Atmos. Res., 90, 338-355, https://doi.org/10.1016/j.atmosres.2008.08.014, 2008.

O'Dowd, C., Ceburnis, D., Ovadnevaite, J., Vaishya, A., Rinaldi, M., and Facchini, M. C.: Do anthropogenic, continental or coastal aerosol sources impact on a marine aerosol signature at Mace Head?, Atmos. Chem. Phys., 14, 10687-10704, https://doi.org/10.5194/acp-14-10687-2014, 2014.

O'Dowd, C. D., Becker, E., and Kulmala, M.: Mid-latitude North-Atlantic aerosol characteristics in clean and polluted air, Atmos. Res., 58, 167-185, https://doi.org/10.1016/S01698095(01)00098-9, 2001

O’Dowd, C. D., Facchini, M. C., Cavalli, F., Ceburnis, D., Mircea, M., Decesari, S., Fuzzi, S., Yoon, Y. J., and Putaud, J. P.: Biogenically driven organic contribution to marine aerosol, Nature, 431, 676-680, https://doi.org/10.1038/nature02959, 2004.

Painemal, D. and Zuidema, P.: Assessment of MODIS cloud effective radius and optical thickness retrievals over the Southeast Pacific with VOCALS-REx in situ measurements, J. Geophys. Res.-Atmos., 116, D24206, https://doi.org/10.1029/2011jd016155, 2011
Paluch, I. R.: Entrainment Mechanism in Colorado Cumuli, J. Atmos. Sci., 36, 2467-2478, https://doi.org/10.1175/15200469(1979)036<2467:TEMICC>2.0.CO;2, 1979.

Petters, M. D. and Kreidenweis, S. M.: A single parameter representation of hygroscopic growth and cloud condensation nucleus activity, Atmos. Chem. Phys., 7, 1961-1971, https://doi.org/10.5194/acp-7-1961-2007, 2007.

Pinsky, M., Khain, A., Mazin, I., and Korolev, A.: Analytical estimation of droplet concentration at cloud base, J. Geophys. Res. Atmos., 117, D18211, https://doi.org/10.1029/2012jd017753, 2012.

Pringle, K. J., Tost, H., Pozzer, A., Pöschl, U., and Lelieveld, J.: Global distribution of the effective aerosol hygroscopicity parameter for CCN activation, Atmos. Chem. Phys., 10, 52415255, https://doi.org/10.5194/acp-10-5241-2010, 2010.

Raatikainen, T., Nenes, A., Seinfeld, J. H., Morales, R., Moore, R. H., Lathem, T. L., Lance, S., Padro, L. T., Lin, J. J., Cerully, K. M., Bougiatioti, A., Cozic, J., Ruehl, C. R., Chuang, P. Y., Anderson, B. E., Flagan, R. C., Jonsson, H., Mihalopoulos, N., and Smith, J. N.: Worldwide data sets constrain the water vapor uptake coefficient in cloud formation, P. Natl. Acad. Sci. USA 110, 3760-3764, doi10.1073/pnas.1219591110, 2013.

Raes, F., Bates, T., McGovern, F., and Van Liedekerke, M.: The 2nd Aerosol Characterization Experiment (ACE-2): general overview and main results, Tellus B, 52, 111-125, https://doi.org/10.1034/j.1600-0889.2000.00124.x, 2000.

Reutter, P., Su, H., Trentmann, J., Simmel, M., Rose, D., Gunthe, S. S., Wernli, H., Andreae, M. O., and Pöschl, U.: Aerosol- and updraft-limited regimes of cloud droplet formation: influence of particle number, size and hygroscopicity on the activation of cloud condensation nuclei (CCN), Atmos. Chem. Phys., 9, 7067 7080, https://doi.org/10.5194/acp-9-7067-2009, 2009.

Rinaldi, M., Facchini, M. C., Decesari, S., Carbone, C., Finessi, E., Mircea, M., Fuzzi, S., Ceburnis, D., Ehn, M., Kulmala, M., de Leeuw, G., and O'Dowd, C. D.: On the representativeness of coastal aerosol studies to open ocean studies: Mace Head - a case study, Atmos. Chem. Phys., 9, 9635-9646, https://doi.org/10.5194/acp-9-9635-2009, 2009.

Roberts, G. C., Andreae, M. O., Zhou, J. C., and Artaxo, P.: Cloud condensation nuclei in the Amazon Basin: "Marine" conditions over a continent?, Geophys. Res. Lett., 28, 2807-2810, https://doi.org/10.1029/2000g1012585, 2001.

Roberts, G. C. and Nenes, A.: A continuous-flow streamwise thermal-gradient $\mathrm{CCN}$ chamber for atmospheric measurements, Aerosol Sci. Technol., 39, 206-221, https://doi.org/10.1080/027868290913988, 2005.

Roberts, G. C., Ramana, M. V., Corrigan, C., Kim, D., and Ramanathan, V.: Simultaneous observations of aerosolcloud-albedo interactions with three stacked unmanned aerial vehicles, P. Natl. Acad. Sci. USA, 105, 7370-7375, https://doi.org/10.1073/pnas.0710308105, 2008.

Rosenfeld, D., Williams, E., Andreae, M. O., Freud, E., Pöschl, U., and Rennó, N. O.: The scientific basis for a satellite mission to retrieve $\mathrm{CCN}$ concentrations and their impacts on convective clouds, Atmos. Meas. Tech., 5, 2039-2055, https://doi.org/10.5194/amt-5-2039-2012, 2012.

Rosenfeld, D., Fischman, B., Zheng, Y., Goren, T., and Giguzin, D.: Combined satellite and radar retrievals of drop concentration and 
CCN at convective cloud base, Geophys. Res. Lett., 41, 32593265, https://doi.org/10.1002/2014g1059453, 2014.

Rosenfeld, D., Zheng, Y., Hashimshoni, E., Poehlker, M. L., Jefferson, A., Poehlker, C., Yu, X., Zhu, Y., Liu, G., Yue, Z., Fischman, B., Li, Z., Giguzin, D., Goren, T., Artaxo, P., Barbosa, H. M. J., Poeschl, U., and Andreae, M. O.: Satellite retrieval of cloud condensation nuclei concentrations by using clouds as CCN chambers, P. Natl. Acad. Sci. USA, 113, 5828-5834, https://doi.org/10.1073/pnas.1514044113, 2016.

Russell, L. M., Lenschow, D. H., Laursen, K. K., Krummel, P. B., Siems, S. T., Bandy, A. R., Thornton, D. C., and Bates, T. S.: Bidirectional mixing in an ACE 1 marine boundary layer overlain by a second turbulent layer, J. Geophys. Res., 103, 16411-16432, 1998.

Russell, L. M. and Seinfeld, J. H.: Size- and composition-resolved externally mixed aerosol model, Aerosol Sci. Technol., 28, 403416, https://doi.org/10.1080/02786829808965534, 1998.

Russell, L. M., Seinfeld, J. H., Flagan, R. C., Ferek, R. J., Hegg, D. A., Hobbs, P. V., Wobrock, W., Flossmann, A. I., O'Dowd, C. D., Nielsen, K. E., and Durkee, P. A.: Aerosol dynamics in ship tracks, J. Geophys. Res.-Atmos., 104, 31077-31095, https://doi.org/10.1029/1999jd900985, 1999.

Sanchez, K. J., Russell, L. M., Modini, R. L., Frossard, A. A., Ahlm, L., Corrigan, C. E., Roberts, G. C., Hawkins, L. N., Schroder, J. C., Bertram, A. K., Zhao, R., Lee, A. K. Y., Lin, J. J., Nenes, A., Wang, Z., Wonaschuetz, A., Sorooshian, A., Noone, K. J., Jonsson, H., Toom, D., Macdonald, A. M., Leaitch, W. R., and Seinfeld, J. H.: Meteorological and aerosol effects on marine cloud microphysical properties, J. Geophys. Res.-Atmos., 121, 41424161, https://doi.org/10.1002/2015jd024595, 2016.

Schubert, W. H., Wakefield, J. S., Steiner, E. J., and Cox, S. K.: Marine stratocumulus convection, 1 governing equations and horizontally homogeneous solutions, J. Atmos. Sci., 36, 1286-1307, https://doi.org/10.1175/15200469(1979)036<1286:mscpig>2.0.co;2, 1979.
Sollazzo, M. J., Russell, L. M., Percival, D., Osborne, S., Wood, R., and Johnson, D. W.: Entrainment rates during ACE-2 Lagrangian experiments calculated from aircraft measurements, Tellus B, 52, 335-347, https://doi.org/10.1034/j.1600-0889.2000.00010.x, 2000.

Stephens, G. L.: Radiation Profiles in Extended Water Clouds 2, Parameterization Schemes, J. Atmos. Sci., 35, 2123-2132, https://doi.org/10.1175/15200469(1978)035<2123:rpiewc<2.0.co;2, 1978.

Stevens, B.: Entrainment in stratocumulus-topped mixed layers, Q. J. Roy. Meteor. Soc., 128, 2663-2690, https://doi.org/10.1256/qj.01.202, 2002.

Stull, R. B.: An Introduction to Boundary Layer Meteorology, Kluwer Academic, Dordrecht, 574-576, 1988.

Turton, J. D. and Nicholls, S.: A Study of the DiurnalVariation of Stratocumulus Using a Multiple Mixed Layer Model, Q. J. Roy. Meteor. Soc., 113, 969-1009, https://doi.org/10.1256/smsqj.47710, 1987.

Tzivion, S., Feingold, G., and Levin, Z.: An efficient numerical solution to the stochastic collection equation, J. Atmos. Sci., 44, 3139-3149, https://doi.org/10.1175/15200469(1987)044<3139:aenstt>2.0.co;2, 1987.

Wildmann, N., Ravi, S., and Bange, J.: Towards higher accuracy and better frequency response with standard multi-hole probes in turbulence measurement with remotely piloted aircraft (RPA), Atmos. Meas. Tech., 7, 1027-1041, https://doi.org/10.5194/amt7-1027-2014, 2014.

Zhou, X., Kollias, P., and Lewis, E. R.: Clouds, Precipitation, and Marine Boundary Layer Structure during the MAGIC Field Campaign, J. Climate, 28, 2420-2442, https://doi.org/10.1175/jcli-d14-00320.1, 2015. 